\title{
Optical measurement of voltage sensing by endogenous ion channels
}

Authors

Parashar Thapa $^{1 \ddagger}$, Robert Stewart ${ }^{1 \ddagger}$, Rebecka J. Sepela ${ }^{1}$, Oscar Vivas ${ }^{2}$, Laxmi K. Parajuli ${ }^{2}$, Mark Lillya $^{1}$, Sebastian Fletcher-Taylor ${ }^{1,3}$, Bruce E. Cohen ${ }^{3}$, Karen Zito ${ }^{2}$, Jon T. Sack ${ }^{1 *}$

${ }^{1}$ Department of Physiology and Membrane Biology, University of California, Davis, CA 95616

${ }^{2}$ Center for Neuroscience, University of California, Davis, CA 95616

${ }^{3}$ Molecular Foundry and Division of Molecular Biophysics \& Integrated Bioimaging, Lawrence Berkeley National Laboratory, Berkeley, CA 94720

$\$$ Authors contributed equally to this work

*Correspondence to jsack@ucdavis.edu 


\section{Abstract}

2 A primary goal of molecular physiology is to understand how conformational changes of

3 proteins affect the function of cells, tissues, and organisms. Here, we describe an imaging

4 method for measuring the conformational changes of the voltage sensors of endogenous ion

5 channel proteins within live tissue. We synthesized a fluorescent variant of a peptidyl toxin, that

6 is compatible with two-photon excitation microscopy. This fluorescent probe targets the voltage

7 sensors of $\mathrm{Kv} 2$ proteins, which form potassium channels and plasma membrane-endoplasmic

8 reticulum junctions. We develop a statistical thermodynamic model to calculate behavior of

9 unlabeled Kv2 voltage sensors from fluorescence images. Two-photon excitation imaging of rat

10 brain slices reveals coupling between membrane potential and the conformation of endogenous

11 neuronal Kv2 proteins. This quantitative imaging method enables measurement of the coupling

12 of conformational state with function of an endogenous protein in tissue, without genetic

13 modification. 


\section{Introduction}

2 To move the field of voltage-sensitive physiology forward, we need new tools that indicate when

3 and where voltage-sensitive conformational changes in endogenous proteins occur. Many classes

4 of transmembrane proteins have been found to be voltage sensitive (Bezanilla 2008). One

5 important class of voltage-sensitive proteins is the voltage gated ion channels.

6 Electrophysiological techniques have enabled extensive studies into the voltage-sensitivity of

7 ionic conductances, primarily under reductionist experimental conditions where the channels

8 have been removed from their native tissue. In addition to their canonical function as ion-

9 conducting channels, voltage gated ion channel proteins have nonconducting functions which are

10 independent of their ion conducting functions (Kaczmarek 2006). These nonconducting protein

11 functions are largely inaccessible to study by electrophysiology, and are more poorly understood.

12 Novel approaches are needed to learn more about voltage-sensing in intact tissues and to unlock

13 the mysterious realm of nonconducting voltage-sensitive physiology. Here, we present a new

14 approach to image the conformational changes of endogenous voltage-sensitive proteins in living

15 tissue.

17 We have developed a new protein imaging tool, an Endogenous ㄴoltage-sensor $\underline{\text { Activity }}$ Probe

18 (EVAP), which dynamically labels living tissue to reveal the spatiotemporal conformational

19 status of endogenous proteins. Here we report synthesis, validation, and measurements using an

20 EVAP which reports the conformational state of the voltage sensor of endogenous Kv2 proteins.

$21 \mathrm{Kv} 2$ proteins form voltage-gated $\mathrm{K}^{+}$channels, and regulate a wide variety of physiological

22 responses in tissues throughout the body (Bocksteins 2016). Electrophysiological approaches can

23 detect the voltage-sensitive $\mathrm{K}^{+}$conductance of $\mathrm{Kv} 2$ channels. However, the majority of Kv2

24 proteins on cell surface membranes do not function as channels, they are nonconducting

25 (Benndorf et al. 1994, O’Connell et al. 2010, Malin et al. 2013). Kv2 proteins dynamically

26 regulate cellular physiology by nonconducting functions (Antonucci et al. 2001, Singer-Lahat et

27 al. 2007, Feinshreiber et al. 2010, X. Q. Dai et al. 2012, Fox et al. 2015, Johnson et al. 2018,

28 Kirmiz, Palacio et al. 2018, Kirmiz, Vierra et al. 2018, Kirmiz et al. 2019, Vierra et al. 2019).

29 The Kv2 EVAP reports on the conformation of Kv2 voltage sensors independently from ion

30 conductance, enabling the study of Kv2's nonconducting physiological functions. We present 
1 this EVAP both as a useful research tool, and as a prototype molecular probe for imaging voltage

2 sensing by endogenous proteins, in tissue, with molecular specificity.

\section{Voltage sensor coupling in voltage gated ion channels}

$5 \mathrm{Kv} 2$ proteins are members of the voltage-gated cation channel superfamily. The voltage sensors of proteins in this superfamily are comprised of a bundle of four transmembrane helices termed S1-S4 (Long et al. 2005, 2007). The S4 helix contains positively charged arginine and lysine residues, gating charges, which respond to voltage changes by moving through the transmembrane electric field (Aggarwal \& MacKinnon 1996, Seoh et al. 1996, Islas \& Sigworth 1999). When voltage sensor domains encounter a transmembrane voltage that is more negative

11 on the inside of the cell membrane, voltage sensors are biased towards resting conformations, or

12 down states, in which gating charges are localized intracellularly. When voltage becomes more

13 positive, gating charges translate towards the extracellular side of the membrane, and voltage

14 sensors are progressively biased towards up states, in a process of voltage activation (Armstrong

15 \& Bezanilla 1973, Zagotta et al. 1994, Tao et al. 2010, Xu et al. 2019). Voltage sensor

16 activation is coupled to the conductance gate of voltage gated ion channels, and can also be

17 coupled to nonconducting protein functions. To study the coupling of voltage sensors to these

18 functions, it is essential to measure voltage sensor activation itself. Conformational changes of

19 voltage sensors have been detected with electrophysiological measurements of gating currents

20 (Armstrong \& Bezanilla 1973, M. F. Schneider \& Chandler 1973, Bezanilla 2018) or by optical

21 measurements from fluorophores covalently attached to voltage sensors by genetic encoding (Lin

22 \& Schnitzer 2016) and/or by chemical engineering (G. Zhang et al. 2015). However,

23 experimental limitations prevent these existing techniques from measuring conformational

24 changes of voltage sensors of most endogenous proteins: gating currents can only be measured

25 when the proteins are expressed at high density in a voltage-clamped membrane; engineered

26 proteins differ from endogenous channels; and introducing point mutations and conjugated

27 fluorophores into voltage sensors alters structure and function. Here, we develop a different

28 strategy, EVAPs that dynamically label endogenous voltage sensors to reveal conformational

29 states, and apply this strategy to Kv2 proteins. 


\section{Kv2 proteins have important nonconducting functions.}

2 Mammals express two Kv2 proteins, Kv2.1 and Kv2.2, which homo- or hetero-tetramerize to

3 form the pore of voltage-gated potassium channels (Frech et al. 1989, Trimmer 1991, Kihira et

4 al. 2010, Bishop et al. 2015). Kv2 proteins contribute to cell physiology in a variety of contexts

5 ranging from neuronal firing (Du et al. 2000, Liu \& Bean 2014, Speca et al. 2014, Hönigsperger

6 et al. 2017), visual transduction (Gayet-Primo et al. 2018), muscle contraction (H. Xu et al.

7 1999, Amberg \& Santana 2006), cell division (Cobb et al. 2015), apoptosis (Pal et al. 2003), and

8 hormone secretion (Singer-Lahat et al. 2007, Feinshreiber et al. 2010, X. Q. Dai et al. 2012).

9 However, the majority ( $73 \%$ to more than $99 \%$ ) of the Kv2 proteins on cell surface membranes

10 are nonconducting (Benndorf et al. 1994, O'Connell et al. 2010, Fox et al. 2013). These

11 nonconducting $\mathrm{Kv} 2$ proteins have voltage sensor movement that is decoupled from pore opening

12 (Fox et al. 2013). The nonconducting functions of Kv2 proteins are an area of intense current

13 interest. Kv2 nonconducting include regulation of plasma membrane-endoplasmic reticulum

14 junctions (Antonucci et al. 2001, Fox et al. 2015, Johnson et al. 2018, Kirmiz, Palacio et al.

15 2018, Kirmiz, Vierra et al. 2018), phosphoinositide homeostasis (Kirmiz et al. 2019), calcium

16 signaling (Vierra et al. 2019), and exocytosis (Singer-Lahat et al. 2007, Feinshreiber et al. 2010),

17 and insulin secretion (X. Q. Dai et al. 2012). Movements of intracellular Kv2 domains are

18 voltage-sensitive (Kobrinsky et al. 2006), but the degree of coupling between voltage sensors

19 and Kv2's intracellular binding partners is unclear.

21 New means are needed to address questions about coupling of voltage sensor movements to

22 native functions. We have designed a molecular tool that enables researchers to image activation

23 of endogenous voltage sensors. Our optical probe selectively reports the conformational state of

$24 \mathrm{Kv} 2$ voltage sensors in living tissue, and the functional coupling of voltage sensor movements.

25 Understanding whether voltage sensor movement is coupled to specific functions will establish

26 whether these functions are themselves responsive to membrane potential.

GxTX-594 is a molecular probe that enables investigation of Kv2 voltage sensing in living

29 brain slices.

30 To image activation of native Kv2 proteins, we exploit the conformation-selective binding of the

31 tarantula peptide guangxitoxin-1E (GxTX) to image where the voltage sensors of Kv2 proteins 
1 adopt a specific resting conformation in tissue. We synthesized GxTX-594, a fluorescent

2 derivative of GxTX that is compatible with two-photon excitation imaging through light-

3 scattering tissue. This EVAP equilibrates with Kv2 proteins on the time scale of seconds,

4 revealing the probability (averaged over time) that unbound voltage sensors are resting or active.

5 We develop a method to calculate the average conformational status of unlabeled Kv2 proteins

6 from images of GxTX-594 fluorescence. We deploy the GxTX-594 probe in brain slices and

7 image voltage-sensitive fluorescence changes that elucidate the spatiotemporal pattern of

8 conformational changes of endogenous neuronal Kv2 proteins. This EVAP approach provides an

9 imaging technique to study conformational changes of voltage-sensitive proteins in samples that

10 have not (or cannot) be genetically modified. 


\section{Results}

2 To create an optical probe of Kv2 voltage sensors, we used solid-phase peptide synthesis to

3 generate a variant of GxTX, an amphiphilic 36-amino acid cystine knot peptide. GxTX

4 partitions into the outer leaflet of the plasma membrane bilayer where it selectively binds to

5 membrane-embedded voltage sensors of Kv2 proteins (Milescu et al. 2009, Tilley et al. 2014,

6 Gupta et al. 2015). We synthesized Ser13Cys GxTX, where the free "spinster" thiolate side

7 chain (Shimony et al. 1994) of cysteine 13 is predicted to extend into extracellular solution when

8 the peptide is bound to a voltage sensor. GxTX-1E folds by formation of 3 internal disulfides,

9 and cysteine 13 was differentially protected during oxidative refolding to direct chemoselective

10 conjugation (Tilley et al. 2014). Following refolding and thiol deprotection, the maleimide

11 derivative of Alexa Fluor 594, a persulfonated Texas Red analog, was condensed with the free

12 thiol, and Ser13Cys(Alexa Fluor 594) GxTX-1E (called "GxTX-594” throughout) was purified

13 and tested for activity against Kv2.1 (Fig. 1 and Fig 1 Supplement 1). These results demonstrate

14 that GxTX-594 retains bioactivity against Kv2 proteins. Alexa Fluor 594 exhibits a large two-

15 photon absorption cross-section and ample spectral separation from green fluorescent protein

16 (GFP), making it well-suited for multiplexed, two-photon excitation imaging experiments (Zito

17 et al. 2004).

\section{GxTX-594 colocalizes with Kv2.1 and Kv2.2}

20 We first assessed whether GxTX-594 labels Kv2 proteins. Mammals have two Kv2 pore-forming

21 subunits, Kv2.1 and Kv2.2, both of which are expressed in neurons throughout the brain

22 (Trimmer 1991, Kihira et al. 2010, Bishop et al. 2015). CHO-K1 cells were transfected with

23 either a rat Kv2.1-GFP or Kv2.2-GFP construct. While the CHO-K1 cell line has little, if any,

24 endogenous $\mathrm{K}^{+}$current (Gamper et al. 2005), transfection with either Kv2.1-GFP or Kv2.2-GFP

25 yielded delayed rectifier $\mathrm{K}^{+}$currents (Fig 6 Supplement 1 A, top two rows). When imaged two

26 days post transfection, Kv2.1-GFP and Kv2.2-GFP fluorescence appeared at the surface

27 membrane of the transfected CHO cells, and the fluorescence was localized predominantly to the

28 glass-adhered basal surface, where it adopted a clustered morphology (Fig 1 A). Clustered basal

29 expression is a hallmark of Kv2 localization in neurons and other mammalian cell lines when

30 they are adhered to glass (Shi et al. 1994, Antonucci et al. 2001). After incubation with

31 membrane-impermeant GxTX-594 (100 nM for 5 minutes), GxTX-594 fluorescence localized to 
1 regions with Kv2-GFP signal (Fig 1 A). GxTX-594, and Kv2.1-GFP or Kv2.2-GFP, had Pearson

2 correlation coefficients that averaged 0.86 or 0.80 , respectively, verifying a high degree of

3 colocalization of both Kv2 proteins with GxTX-594 (Fig 1 B). The ratio of GxTX-594 to GFP

4 fluorescence intensity was similar for Kv2.1-GFP or Kv2.2-GFP (Fig 1 C), consistent with the

5 lack of discrimination of GxTX between Kv2.1 and Kv2.2 (Herrington et al. 2006).

\section{GxTX-594 binds Kv2.1 in the presence of its neuronal auxiliary subunit AMIGO-1}

8 In neurons, Kv2 proteins colocalize with an auxiliary subunit, AMIGO-1 (Peltola et al. 2011,

9 Bishop et al. 2018). AMIGO-1 is a single-pass transmembrane protein with a large extracellular

10 domain, an architecture similar to auxiliary subunits of voltage-gated sodium channels, Kv4

11 channels, or BK channels that modulate binding of peptide toxins to the channels (Xia et al.

12 1999, Gilchrist et al. 2013, Maffie et al. 2013). To determine if AMIGO-1 affects GxTX-594

13 labeling, Kv2.1-expressing cells were transiently transfected with an AMIGO-1-YFP construct.

14 For these experiments, Kv2.1 was expressed in a CHO-K1 cell line stably transfected with rat

15 Kv2.1 under control of a tetracycline-inducible promoter (Kv2.1-CHO) (Trapani \& Korn 2003).

$16 \mathrm{Kv} 2.1$ expression was induced with minocycline 48 hours prior to experiments, such that all

17 Kv2.1-CHO cells expressed Kv2.1. In this expression system, Kv2.1 is not tagged with a

18 fluorescent protein. AMIGO-1-YFP fluorescence was observed in clusters at the basal membrane

19 (Fig 2 A) similar to Kv2.1-GFP (Fig 1 A). GxTX-594 colocalized with AMIGO-1-YFP (Fig 2

20 A). Pearson's correlation coefficient indicated colocalization between AMIGO-1-YFP and

21 GxTX-594, consistent with AMIGO-1 colocalizing with clustered Kv2.1 (Fig 2 B). GxTX-594

22 also labeled cells that did not express AMIGO-1 (Fig 2 A). We tested whether binding of GxTX-

23594 to Kv2.1 is different between cells which do or do not express AMIGO-1. Increasing

24 concentrations of GxTX-594 were applied to cells and the relationship between GxTX-594

25 fluorescence intensity and dose was quantified for cells expressing AMIGO-1-YFP (green) and

26 cells not expressing AMIGO-1-YFP (blue) (Fig 2 C). A Langmuir binding isotherm was fit to

27 GxTX-594 fluorescence intensity (lines, Fig 2 D), and resulted in an indistinguishable

28 dissociation constant between cells expressing AMIGO-1-YFP (27 $\pm 14 \mathrm{nM})$ and cells not

29 expressing AMIGO-1-YFP $(26.9 \pm 8.3 \mathrm{nM})$. Thus, there is no indication that AMIGO-1 disrupts

30 the GxTX-594-Kv2 interaction. 


\section{GxTX-594 fluorescence dynamics report Kv2 voltage activation}

2 To understand the relationship between voltage sensor conformational change and GxTX-594

3 fluorescence, we determined how fluorescence intensity on cells expressing Kv2.1 responds to

4 changes in membrane voltage. For these experiments, Kv2.1-CHO cells were incubated in

5 minocycline for 48 hours to induce Kv2.1 expression. Kv2.1-CHO cells were then incubated for

65 minutes in a bath solution containing $100 \mathrm{nM}$ GxTX-594 before dilution with extracellular

7 solution to $9 \mathrm{nM}$, and imaged at least 9 minutes after dilution. Fluorescence intensity images

8 were generated from airy disk confocal imaging of cells voltage-clamped in the whole-cell patch

9 clamp configuration. Unlike images shown in Fig 1, the imaging plane for voltage-clamp

10 experiments was above the glass-adhered surface. This higher plane was chosen because GxTX-

11594 labeling kinetics are slower in the highly restricted extracellular space where the plasma

12 membrane adheres to glass (Fig 3 Supplement 1).

14 To measure voltage-dependent fluorescence changes, cells were held at $-80 \mathrm{mV}$ and stepped to

15 indicated test potentials (Fig 3 A). A region of interest (ROI) corresponding to the cell surface

16 was manually identified and average fluorescence intensity quantified from time-lapse

17 sequences. Average fluorescence intensity from the cell surface was background-subtracted

18 using the average fluorescence intensity from an ROI in a region without cells. Both the

19 amplitude and kinetics of fluorescence change from cell surface ROIs are sensitive to voltage

20 (Fig 3 B), similar to prior findings with GxTX-550 (Tilley et al. 2014). We observed that cells

21 exhibited a baseline fluorescence intensity above background, even when given a $+80 \mathrm{mV}$

22 depolarizing voltage stimulus (Fig 3 B). This residual fluorescence varied between cells (Fig 3

23 C) and was potentially due to internalized GxTX-594 and/or autofluorescence. However, much

24 of the residual fluorescence appeared to be localized to the cell surface membrane (Fig $3 \mathrm{~A}$ ). As

25 such membrane labeling was not present on $\mathrm{CHO}$ cells in the absence of $\mathrm{Kv} 2$ proteins (Fig 6),

26 this fluorescence could indicate a population of Kv2.1 that resides at the cell surface and binds

27 GxTX-594 in a fashion that renders the Kv2.1-GxTX complex insensitive to voltage.

29 To compare labeling intensity between cells, the initial fluorescence at a holding potential of -80

$30 \mathrm{mV}$ was normalized to $100 \% \mathrm{~F} / \mathrm{F}_{\text {init }}$, and residual fluorescence after a $+80 \mathrm{mV}$ step was

31 normalized to $0 \% F / F_{\text {init }}$ (Fig $3 \mathrm{D}$ ). The fluorescence-voltage response was fit with a Boltzmann 
1 function with a half maximal voltage midpoint $\left(V_{1 / 2}\right)$ of $-27 \mathrm{mV}$ and a steepness $(z)$ of 1.4

2 elementary charges $\left(e_{0}\right)$ (Fig $3 \mathrm{D}$, black line). This is strikingly similar to the voltage dependence

3 of integrated gating charge from Kv2.1-CHO cells, without any GxTX present $V_{1 / 2}=-26 \mathrm{mV}, z=$

$4 \quad 1.6 e_{0}$ (Tilley et al. 2019).

To determine the temporal response of GxTX-594 labeling to voltage change, we compared rates of fluorescence change $\left(k_{\Delta F}\right)$ to varying step potentials (Fig $3 \mathrm{E}$ ) in the same data set that were analyzed in Fig 3 D. We quantified rates of fluorescence change $\left(k_{\Delta F}\right)$ by fitting a monoexponential function:

$10 \quad F=F_{\infty}+F_{0} e^{\frac{\left(t-t_{0}\right)}{\tau}} \quad$ (Equation 1)

11 Where $\tau=1 / k_{\Delta F}, t=$ time, $t_{0}=$ time at start of fit, $F=$ fluorescence intensity, $F_{0}=$ fluorescence at

12 start of fit, $F_{\infty}=$ fluorescence after infinite time. In response to voltage steps from a holding

13 potential of $-80 \mathrm{mV}$ to more positive potentials, $k_{\Delta F}$ increased progressively from approximately

$14-40 \mathrm{mV}$ to $+40 \mathrm{mV}$. After a return to $-80 \mathrm{mV}$, labeling occurred at a rate similar to unlabeling

15 at $-40 \mathrm{mV}$, indicating that the rate of relaxation to a labeled/unlabeled equilibrium saturates

16 below $-40 \mathrm{mV}$. There was substantial variability in $k_{\Delta F}$ between cells (Fig $3 \mathrm{E}$ ). We wondered if

17 this could be due to fluctuations in ambient temperature $\left(27-29^{\circ} \mathrm{C}\right)$, given the substantial

18 temperature sensitivity reported for Kv2.1 conductance (F. Yang \& Zheng 2014). However the

19 temperature dependence of $k_{\Delta F}$ indicated that only 1.3 -fold variation could be attributed to a $2^{\circ} \mathrm{C}$

20 temperature variation (Fig 3 Supplement 2), suggesting that there are determinants of $k_{\Delta F}$

21 variability which are intrinsic to individual cells. The $k_{\Delta F^{-}}$-voltage response was fit with a

22 Boltzmann distribution (Eq. 2) resulting in $V_{1 / 2}=+2 \mathrm{mV}$ and $z=1.1 e_{0}$ (Fig $3 \mathrm{E}$, black line).

23 Notably, the dynamic fluorescence responses of GxTX-594 to voltage changes occurred at

24 physiologically relevant potentials, suggesting that changes in GxTX-594 labeling intensity or

25 rate could occur in response to changes in cellular electrical signaling.

The relation between voltage sensor activation and GxTX-594 dynamics can be recapitulated

28 by rate theory modeling.

29 To enable translation of the intensity of fluorescence from GxTX-594 on a cell surface into a

30 measure of conformational change, we developed a model relating cell labeling to voltage sensor

31 activation. The framework of this model is generalizable to fluorescent molecular probes that 
1 report conformational changes by a change in binding affinity. In our model of EVAP labeling,

2 the ratio of labeled to unlabeled Kv2 in a membrane is determined by confomational change

3 from resting to activated altering the binding and unbinding rates of the EVAP (Scheme I).

\section{Scheme I}

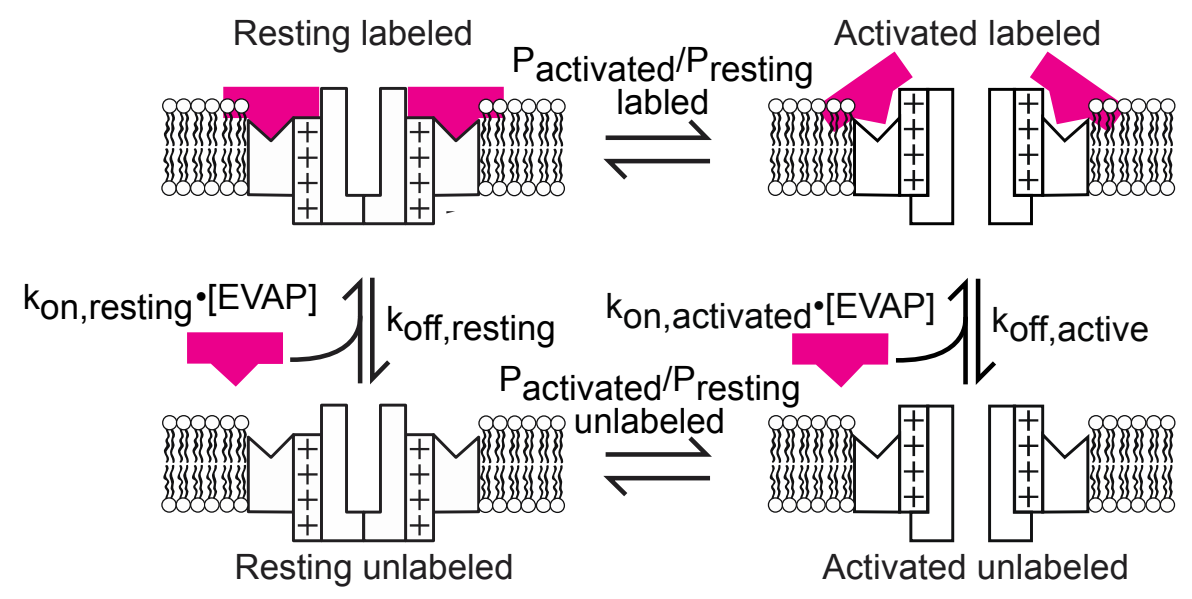

\section{Scheme II}
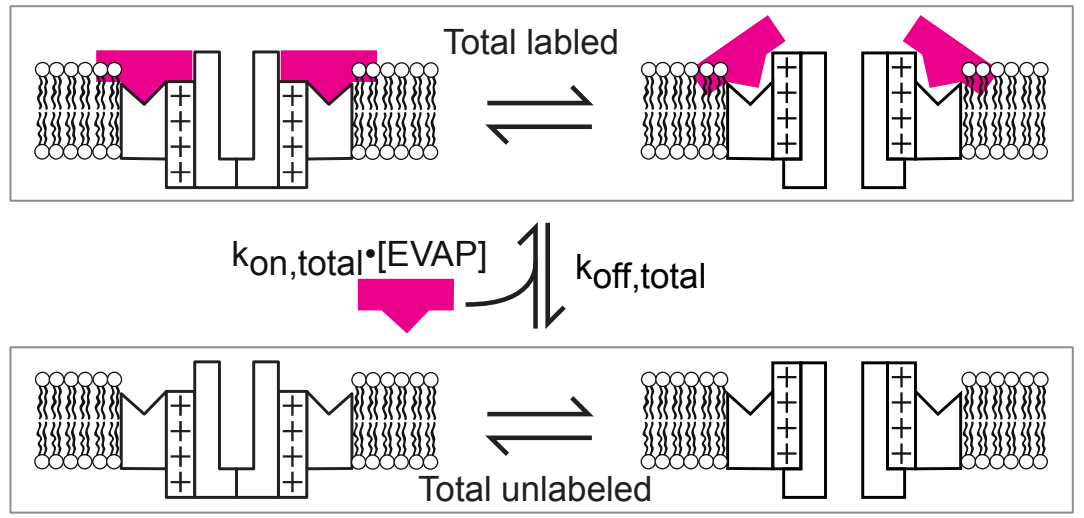

5 The Scheme I model assumes the innate voltage sensitivity of the Kv2 subunit is solely responsible for controlling voltage dependence. Labeling is voltage-dependent because the binding and unbinding rates are different for resting and activated conformations of voltage

8 sensors. When voltage sensors change from resting to activated conformations, the binding rate

9 of the EVAP decreases and the unbinding rate increases. When the membrane voltage is held

10 constant for sufficient time, the proportions of labeled and unlabeled proteins reach an

11 equilibrium. Scheme I assumes that voltage sensor conformational changes equilibrate much

12 faster than EVAP binding or unbinding, such that binding and unbinding are the rate-limiting

13 steps. EVAP labeling requires seconds to equilibrate (Fig 3), whereas Kv2 channel gating

14 equilibrates in milliseconds (Tilley et al. 2019), three orders of magnitude more quickly. This 
1 much faster voltage sensor equilibration justifies our simplifying approximation that voltage

2 sensor conformations achieve equilibrium so quickly that only their distribution at equilibrium

3 impacts the kinetics of labeling and unlabeling. Voltage-activation of Kv2 channels involve

4 many conformational changes (Scholle et al. 2004, Jara-Oseguera et al. 2011, Tilley et al. 2019).

5 However, models which presume independent activation of a voltage sensor in each of the four

6 Kv2.1 subunits accurately predict many aspects of voltage activation and voltage sensor toxin

7 binding (Lee et al. 2003, Tilley et al. 2019). Thus, we found it reasonable to model voltage

8 sensor activation of Kv2 proteins as a single, rapid transition of each voltage sensor from a

9 resting conformation to an activated conformation. With this model, at any given voltage, there

10 is a probability that a voltage sensor is either in its resting conformation $\left(P_{\text {resting }}\right)$, or in its

11 activated conformation $\left(P_{\text {activated }}\right)$, such that $P_{\text {activated }}=\left(1-P_{\text {resting }}\right)$. The equilibrium for voltage

12 sensor activation is then a ratio of activated to resting voltage sensors $\left(P_{\text {activated }} / P_{\text {resting }}\right)$ in which

$14 \quad \frac{P_{\text {activated }}}{P_{\text {resting }}}$ unlabeled $=e^{\left(V-V_{1 / 2, \text { unlabeled }}\right) \frac{z F}{R T}}$

Equation $2 \mathrm{a}$

$15 \quad \frac{P_{\text {activated }}}{P_{\text {resting }}}$ labeled $=e^{\left(V-V_{1 / 2, \text { labeled }}\right) \frac{z F}{R T}}$

Equation $2 b$

17 where $V_{1 / 2}$ is the voltage where $P_{\text {activated }} / P_{\text {resting, }}=1, z$ is the number of elementary charges

18 determining voltage dependence, $F$ is the Faraday constant, $R$ is the ideal gas constant, and $T$ is

19 absolute temperature. In a prior study, we fit the conductance-voltage relation of Kv2.1 with a

20 Boltzmann distribution that yielded $V_{1 / 2}=-31.7 \mathrm{mV}$ with $z=1.5 e_{0}$ for the early movement of 4

21 independent voltage sensors, and found that with a saturating concentration of GxTX the $V_{1 / 2}=$

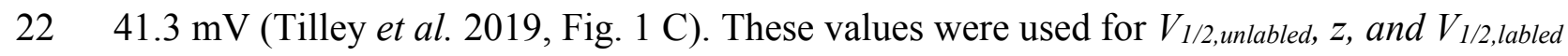

23 respectively (Table 1). To relate voltage sensor activation to labeling and unlabeling, we used

24 microscopic binding $\left(k_{o n}[E V A P]\right)$ and unbinding $\left(k_{o f f}\right)$ rates that are distinct for resting and

25 activated voltage sensors. We estimated values for these rates assuming 
$1 \quad K_{d}=\frac{k_{o f f}}{k_{o n}}$

(Equation 4)

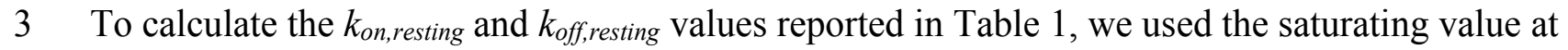

4 negative voltages of the $k_{\Delta F^{-}}$-voltage relation (Fig $3 \mathrm{E}$ ), and $K_{d}$ from dose-response imaging (Fig

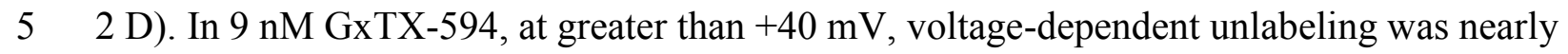

6 complete, indicating that $k_{\text {off,activated }}>>k_{\text {on,activated }}[E V A P]$. We input the saturation of $k_{\Delta F}$ at

7 positive voltages as $k_{\text {off, activated }}($ Fig $3 \mathrm{E}$ ). The slow labeling of activated voltage sensors

8 confounded attempts to measure $k_{\text {on, activated }}$ directly, and we used the statistical thermodynamic

9 principle of microscopic reversibility (Lewis 1925) to constrain $k_{\text {on, activated: }}$

$11 \frac{\frac{P_{\text {activated }}}{P_{\text {resting }}}, \text { labeled }}{\frac{P_{\text {activated }}}{P_{\text {resting }}} \text {,unlabeled }}=\frac{\frac{k_{\text {off, resting }}}{k_{\text {on, resting }}}}{\frac{k_{\text {off, activated }}}{k_{\text {on, activated }}}}$

(Equation 5)

13 At any static voltage, the simplifying assumption that voltage sensors are in continuous

14 equilibrium allows Scheme I to collapse into Scheme II, which has only a single microscopic

15 binding rate, $k_{\text {on,total }}[E V A P]$, and unbinding rate, $k_{\text {off,total. }}$ In Scheme II, $k_{\text {on,total }}$ is a weighted sum

16 of both $k_{\text {on,resting }}$ and $k_{\text {on, activated }}$ from Scheme I. The weights for $k_{\text {on,total }}$ are the relative

17 probabilities that unlabeled voltage sensors are resting or activated, which is determined at any

18 static voltage by an equilibrium constant, $\frac{P_{\text {activated }}}{P_{\text {resting }}}$ unlabeled:

$k_{\text {on }, \text { total }}=k_{\text {on,resting }}[E V A P] \cdot \frac{1}{1+\frac{P_{\text {activated }}}{P_{\text {resting }}} \text { unlabeled }}+k_{\text {on,active }}[E V A P] \cdot \frac{1}{1+\frac{1}{\frac{P_{\text {activated }} \text { unlabeled }}{P_{\text {resting }}}}}$

23 Similarly, $k_{\text {off,total }}$ is determined by the unbinding rate from resting voltage sensors $\left(k_{\text {off,resting }}\right)$ and

24 the unbinding rate from activated voltage sensors ( $k_{\text {off }}$,activated $)$, and weighted such that:

$$
k_{\text {off,total }}=k_{o f f, \text { resting }} \cdot \frac{1}{1+\frac{P_{\text {activated }}}{P_{\text {resting }}} \text { labeled }}+k_{o f f, \text { active }} \cdot \frac{1}{1+\frac{1}{\frac{P_{\text {activated }} \text { labeled }}{P_{\text {resting }}}}}
$$


1 Using $k_{\text {on,total }}$ and $k_{\text {off,total }}$ we can compute $k_{\Delta F}$ using Equation 3. To test the predictive value of the

2 Scheme II model, we compared the predicted $k_{\Delta F}$ to experimental measurements in $9 \mathrm{nM} \mathrm{GxTX-}$

3594 (Fig 3 E, blue line). We found the Scheme II model reasonably reproduced the voltage

4 dependence of Kv2.1 labeling.

The Scheme II model was also used to predict the magnitude of EVAP fluorescence changes on cell surfaces. In theory, the ratio of fluorescence at a test voltage to a prior voltage $\left(F / F_{\text {init }}\right)$ is

$\frac{F}{F_{\text {init }}}=\frac{P_{\text {labeled }}}{P_{\text {labeled,init }}} \quad($ Equation 8$)$

12 The equilibrium $P_{\text {labeled }}$ at any voltage can be determined from microscopic binding rates

13 associated with Scheme II where:

$$
P_{\text {labeled }}=\frac{1}{1+\frac{K_{d, \text { total }}}{[E V A P]}}=\frac{1}{1+\frac{k_{\text {off }, \text { total }}}{k_{\text {on,total } \cdot[E V A P]}}} \quad \text { (Equation 9) }
$$

Using this model, we calculated the fluorescence-voltage relation from $P_{\text {labeled }}$ (Equation 8) and compared these calculated values to our experimental data. The model predicts fluorescence response within the range of the experimental data (Fig $3 \mathrm{D}$, blue line).

\section{Rate theory modeling roughly predicts GxTX-594 labeling during dynamic voltage changes}

22 The Scheme II model relating labeling to voltage sensor activation was developed for static

23 voltages. However, in electrically activated cells, voltage is dynamic. In neurons, action

24 potentials involving Kv2 currents occur on the millisecond time scale (Liu \& Bean 2014, Kimm

25 et al. 2015), orders of magnitude faster than the GxTX-594 response. Thus, the slow EVAP

26 response will integrate voltage fluctuations occurring over many seconds. The Scheme II model

27 assumes that voltage sensors are in continuous equilibrium, and this assumption breaks down

28 when voltage is rapidly changing, as Kv2 voltage sensor movements with or without GxTX

29 require milliseconds to equilibrate (Tilley et al. 2019). We assessed whether the Scheme II

30 model retains predictive power in response action potentials by stimulating cells with brief 
1 voltage steps that crudely mimic action potentials. We stimulated GxTX-594 labeled Kv2.1-

2 CHO cells with trains of $2 \mathrm{~ms}$ voltage steps from -80 to $+40 \mathrm{mV}$, and observed a change in cell

3 surface fluorescence (Fig 4 A, B). To assess frequency response, step frequency was varied from

40.02 to $200 \mathrm{~Hz}$. At frequencies higher than $25 \mathrm{~Hz}$, detectable unlabeling occurred (Fig $4 \mathrm{C}$ ), and

$5 k_{\Delta F}$ varied with stimulus frequency (Fig 4 D). Frequency-dependent predictions of $F / F_{\text {init }}$ and $k_{\Delta F}$

6 were made from the Scheme II model. These predictions were calculated assuming the summed

7 probability of being at every voltage determines the overall $P_{\text {labeled. }}$ The general form of our

8 equation relating fluorescence intensity change to a stimulus that varies faster than EVAP

9 labeling is:

$11 F / F_{\text {init }}=\left(P_{V 1} \cdot \Delta F_{V 1}\right)+\left(P_{V 2} \cdot \Delta F_{V 2}\right)+\ldots+\left(P_{V n} \cdot \Delta F_{V n}\right)$

(Equation 10)

13 where $\Delta F_{n}$ is $\Delta F$ at that particular voltage. For voltage steps from -80 to $+40 \mathrm{mV}$ Eq. 10 is:

$F / F_{\text {init }}=\left(P_{40 m V} \cdot \Delta F_{40 m V}\right)+\left(P_{-80 m V} \cdot \Delta F_{-80 m V}\right)$

17 Measured changes in fluorescence intensity were 2- to 3-fold more sensitive to frequency than

18 responses predicted by the Eq. 10 (Fig 4 C, blue line). When the fluorescence intensity changes

19 were fit with a Boltzmann distribution, the fit had a similar slope but the midpoint was at a lower

20 stimulus frequency than the model predictions (Fig 4 C, black line). This discrepancy could be

21 due to Kv2.1 voltage sensors having insufficient time to equilibrate at high stimulus frequencies.

22 The time constant of deactivating gating current decay from Kv2.1-CHO cells was $22 \mathrm{~ms}$ at -80

$23 \mathrm{mV}$ (Tilley et al. 2019). Voltage sensors that fail to deactivate before the next stimulus could

24 lead to an accumulation of activated voltage sensors, and more EVAP unlabeling than predicted

25 by Eq. 10 which assumes continuous equilibrium.

27 The general form of our equation relating fluorescence intensity change to a stimulus that varies

28 faster than EVAP labeling is: 
1 where $P_{V n}$ is the probability over time that the voltage has a particular value and $k_{\Delta F, n}$ is $k_{\Delta F}$ at

2 that particular voltage. For voltage steps from -80 to $+40 \mathrm{mV}$ Eq. 11 is:

$k_{\Delta F}=\left(P_{40 m V} \cdot k_{\Delta F 40 m V}\right)+\left(P_{-80 m V} \cdot k_{\Delta F-80 m V}\right)$

The model produced a frequency dependence of $k_{\Delta F}$ that was within range of the empirical data

7 (Fig 4 D, blue line).

Overall, the response of GxTX-594 labeling to rapidly varying stimuli indicates that the fluorescence response generally follows the predictions of the Scheme II model, although GxTX-

11594 labeling is more sensitive to high frequency stimulation than predicted. As this very simple

12 model recapitulated the general response of an EVAP to static and varying voltage stimuli, we

13 further investigated its predictions of EVAP labeling responses and its utility in interpreting

14 changes in EVAP labeling.

\section{Changes in EVAP labeling report conformational changes of unlabeled Kv2 proteins.}

17 We used the EVAP model to investigate general principles of the relation between voltage sensor activation and labeling. In particular, we are interested in exploiting EVAP labeling to reveal information about voltage sensor activation in the unlabeled Kv2 population, akin to how $\mathrm{Ca}^{2+}$

20 indicators are used to reveal the concentration of free $\mathrm{Ca}^{2+}$. The Scheme I model was used to 21 predict labeling at a series of EVAP concentrations (Fig $5 \mathrm{~A}$ ). While the model was calibrated to

22 fluorescence responses at particular voltages (Fig $5 \mathrm{~A}$, bottom axis), EVAP labeling is not

23 directly sensitive to voltage, but is determined by the probability that voltage sensors are in an

24 activated conformation (Fig 5 A, top axis). As the EVAP binds resting voltage sensors much

25 more rapidly than activated voltage sensors $\left(k_{\text {on,resting }}>>k_{\text {on, activated }}\right)$ the probability that unlabeled

26 voltage sensors are resting determines the labeling rate, and influences $P_{\text {bound }}$. Our model predicts

27 that as the EVAP concentration decreased, the change in labeling $\left(\Delta F / \Delta F_{\max }\right)$

28 asymptotically approaches the probability that unlabeled voltage sensors are resting (Fig 5 A).

29 Even at $100 \mathrm{nM}$ GxTX-594, more than 3 times the $K_{d}$ for the resting conformation, a change in

30 labeling corresponds to a conformational change in the voltage sensors of unlabeled Kv2

31 proteins. At and below the $K_{d}$ for the resting conformation, the change in labeling was nearly 
1 proportionate with voltage sensor conformational change. The predicted rate of fluorescence

2 change $\left(k_{\Delta F}\right)$ approaches a consistent response as EVAP concentration decreased below the $K_{d}$

3 for the resting conformation. Thus, the fluorescence response is similar at EVAP all

4 concentrations below the $K_{d}$ for the resting conformation, when a minority of EVAP binding

5 sites are occupied. This indicates that if the concentration of EVAP applied to a tissue is below

6 the $K_{d}$ for the resting conformation, EVAP dynamics are expected to be consistent throughout a

7 tissue, even if the EVAP concentration is lower due to difficulty penetrating tissue or is

8 otherwise depleted. Overall, a broad qualitative interpretation can be made from EVAP

9 fluorescence changes: a change in labeling indicates that voltage sensors of unlabeled Kv2

10 proteins have changed their probability of being activated.

\section{GxTX-594 selectively labels Kv2 proteins}

13 Armed with a model for interpretation of changes in EVAP labeling, we proceed to determine

14 whether GxTX-594 could reveal conformational changes of endogenous Kv2 proteins. An

15 important consideration in interpreting fluorescence images of tissues is whether cell labeling

16 with the GxTX-594 EVAP could be due to receptors other than Kv2 proteins.

17 Electrophysiological studies have concluded that the native GxTX peptide is selective for Kv2

18 channels, with some off-target modulation of A-type Kv4 channels (Herrington et al. 2006, Liu

19 \& Bean 2014, Speca et al. 2014). However, electrophysiological testing only indicates whether

20 GxTX modulates channels; electrophysiology cannot detect ligands that bind proteins, but do not

21 alter currents (Sack et al. 2013). Furthermore, structural differences between wild-type GxTX

22 and the GxTX-594 variant could potentially alter selectivity among channel protein subtypes.

24 To test whether GxTX-594 binds other voltage-gated $\mathrm{K}^{+}$channel subtypes, we quantified surface

25 labeling and analyzed colocalization of GxTX-594 with a selection of GFP-labeled voltage-gated

$26 \mathrm{~K}^{+}$channel subtypes. A series of GFP-K $\mathrm{K}^{+}$channel protein fusions were identified that express

27 and retain function with a GFP tag: rat Kv4.2-GFP (Shibata et al. 2003), rat Kv1.5-GFP (Li et al.

28 2001), and mouse BK-GFP. Transfection of each of these channel subtypes into CHO cells

29 resulted in voltage-dependent outward currents, consistent with cell surface expression of the $\mathrm{K}^{+}$

30 channels (Fig 6, Supplement 1 A). In imaging analysis, the surface membrane was identified by

31 labeling with a fluorescent wheat germ agglutinin (WGA) conjugate. Transfection of all $\mathrm{K}^{+}$ 
1 channel-GFP constructs resulted in GFP localization at the cell surface, however the majority of

2 the Kv4.2 and Kv1.5 appeared intracellularly retained (Fig 6, Supplement 1 B). Consistent with

3 reports in other cell lines, cell surface localization improved when of Kv4.2 was co-transfected

4 with KChIP2 (Shibata et al. 2003) or Kv1.5 with Kvß2 (Shi et al. 1996) (Fig 6 A). After

5 incubation with $100 \mathrm{nM} \mathrm{GxTX-594}$ for five minutes, cells expressing the GFP-tagged variants of

$6 \mathrm{Kv} 2.1$ and 2.2 became labeled while neither Kv4.2 + KChIP2, nor Kv1.5 + Kv $\beta 2$, nor BK

7 channels were appreciably labeled (Fig 6 A). When the background-subtracted GxTX-594:GFP

8 fluorescence intensity ratio was normalized to GxTX-594:Kv2.1-GFP, this ratio was close to

9 zero for Kv4.2 + KChIP2, Kv1.5 + Kv $\beta 2$, or BK (Fig 6 B), suggesting minimal binding to these

10 channel subtypes. Furthermore, no colocalization was apparent between Kv4.2 + KChIP2, Kv1.5

$11+\mathrm{Kv} \beta 2$, or BK and GxTX-594 (Fig 6 C). A similar set of experiments conducted without the

12 auxiliary subunits of Kv4.2 or Kv1.5 also gave no indication of GxTX-594 labeling of Kv4.2 or

13 Kv1.5 (Fig 6, Supplement 1 B, C, D). We did not conduct a comprehensive survey of all the

14 more than 80 known mammalian proteins containing voltage sensor domains, and thus cannot be

15 certain that GxTX-594 does not bind any other voltage sensors, or other receptors on cell

16 surfaces. However, the lack of labeling of these related voltage-gated $\mathrm{K}^{+}$channels indicates that

17 GxTX-594 does not promiscuously label voltage sensors. In all tests conducted, GxTX-594 was

18 selective for Kv2 proteins.

To determine whether expression of Kv2 proteins embedded in tissue can be imaged with GxTX594, we overexpressed Kv2.1-GFP in brain slices. We examined rat brain at CA1 pyramidal neurons of the hippocampus. CA1 neurons express Kv2 channels, the physiology of these

23 neurons have been intensively studied, and their electrical properties are relatively homogeneous

24 (Misonou et al. 2005). Organotypic hippocampal slice cultures prepared from postnatal day 5-7

25 rats were sparsely transfected with Kv2.1-GFP, resulting in a subset of neurons displaying green

26 fluorescence. When imaged two to four days after transfection, GFP fluorescence was observed

27 in the plasma membrane surrounding neuronal cell bodies and proximal dendrites (Fig 7

28 Supplement 1 A and B). Six days or more after transfection, Kv2.1-GFP fluorescence organized

29 into clusters on the surface of the cell soma and proximal processes (Fig 7 A, Fig 7 Supplement 1

30 C), a pattern consistent with a prior report of endogenous Kv2.1 in CA1 neurons (Misonou et al.

31 2005). After identifying a neuron expressing Kv2.1-GFP, solution flow into the imaging 
1 chamber was stopped and GxTX-594 was added to the static bath solution to a final

2 concentration of $100 \mathrm{nM}$. After five minutes of incubation, solution flow was restarted, leading to wash-out of GxTX-594 from the imaging chamber. After wash-out, GxTX-594 fluorescence remained colocalized with Kv2.1-GFP (Fig 7, Fig 7 Supplement 1), indicating that GxTX-594 is

5 able to permeate through dense neural tissue and bind to Kv2 proteins on neuronal surfaces. Pearson correlation coefficients confirmed the colocalization of GxTX-594 with Kv2.1-GFP in multiple slices (Fig 7 C). In most images of Kv2.1-GFP expressing neurons, GxTX-594 labeled

8 puncta were observed on neighboring neurons that did not express Kv2.1-GFP, but at intensities 9 that were roughly an order of magnitude dimmer (Fig 7 B, white arrow). The similarity in the 10 labeling patterns are consistent with GxTX-594 labeling endogenous Kv2 proteins. The lack of

11 GxTX-594 labeling of non-Kv2 $\mathrm{K}^{+}$channels, the increased labeling of neurons where Kv2.1-

12 GFP is expressed, and the Kv2-like labeling patterns of CA1 neurons all indicate that GxTX-594 13 selectively labels Kv2 proteins in living brain slices.

\section{GxTX-594 labeling of neurons in brain slice responds to neuronal depolarization}

16 To test whether GxTX-594 labeling of neurons in brain slices is consistent with labeling of

17 endogenous Kv2 voltage sensors, we determined whether GxTX-594 labeling responds to

18 voltage changes. First, we looked for Kv2-like labeling patterns on CA1 pyramidal neurons in

19 untransfected brain slices bathed in $100 \mathrm{nM} \mathrm{GxTX-594.} \mathrm{In} \mathrm{two-photon} \mathrm{excitation} \mathrm{optical} \mathrm{sections}$

20 thinner than the neuronal cell bodies, fluorescent puncta circumscribed dark intracellular spaces

21 (Fig 8 A). This was similar to the patterns of fluorescence in Kv2.1-GFP transfected slices (Fig 7

22 B), and consistent with the punctate expression pattern of Kv2.1 in CA1 pyramidal neurons seen

23 in fixed brain slices (Misonou et al. 2005).

25 We tested whether the punctate fluorescence was voltage-sensitive using voltage clamp. To 26 ensure voltage clamp of the neuronal cell body, slices were bathed in tetrodotoxin to block $\mathrm{Na}^{+}$ 27 channels, and $\mathrm{Cs}^{+}$was included in the patch pipette solution to block $\mathrm{K}^{+}$currents. In each 28 experiment, whole-cell configuration was achieved from a GxTX-594 labeled neuron, and 29 holding potential was set to $-70 \mathrm{mV}$. At this point, time-lapse imaging of a two-photon excitation 30 optical section was initiated. Depolarization to $0 \mathrm{mV}$ resulted in loss of fluorescence from a 31 subset of puncta at the perimeter of the voltage-clamped neuron (Fig 8 B red arrows, 
1 Supplemental Movie). Other fluorescent puncta appeared unaltered by the $0 \mathrm{mV}$ step (Fig 8 B,

2 white arrows).

4 To assess if the apparent stimulus-dependent fluorescence decrease noted in puncta after a

5 voltage step to $0 \mathrm{mV}$ was due to random fluctuations during imaging, we compared fluorescence

6 of the apparent cell membrane region to regions more distal from the voltage-clamped cell body.

7 To quantify this fluorescence change, an ROI 30 pixels $(1.2 \mu \mathrm{m})$ wide containing the apparent

8 membrane of the cell body was compared to other regions within each image (Fig $8 \mathrm{C}$ ). The

9 region containing the membrane of the cell body lost fluorescence during the $0 \mathrm{mV}$ step (Fig 8

10 D, ROI 1) while neither of the regions more distal (ROI 2, ROI 3), nor the intracellular region

11 (ROI 0) showed a similar change. In multiple slices, the voltage-dependent decrease of

12 fluorescence was seen specifically in the region of the voltage-clamped neuronal membrane (Fig

$138 \mathrm{E}$ ). The kinetics of fluorescence response of the voltage-clamped membrane region were

14 similar between slices (Fig 8 F).

16 To determine whether the fluorescence response to depolarization was driven by the Kv2-like

17 puncta on the cell membrane, the fluorescence along a path containing the apparent cell

18 membrane was selected by drawing a path connecting fluorescent puncta surrounding the dark

19 cell body region, and averaging fluorescence in a region 10 pixels wide $(0.4 \mu \mathrm{m})$ centered on this

20 path (Fig $8 \mathrm{G}$, yellow line). The fluorescence intensity along the path of the ROI revealed distinct

21 peaks corresponding to puncta (Fig $8 \mathrm{H}$, red trace). After stepping the neuron to $0 \mathrm{mV}$, the

22 intensity of fluorescence of a subset of puncta lessened (Fig $8 \mathrm{H}$, black trace, peaks 1,3,4,5,8).

23 The Scheme II model predicts a 55\% reduction of fluorescence, but even more reduction is

24 observed in individual fluorescence puncta in brain slice (Fig 8, I blue line). This would be

25 expected if the concentration of GxTX-594 diminished as it penetrated into the brain tissue (Fig

$266 \mathrm{~A})$. In addition to the depolarization-responsive fluorescence puncta, other puncta which

27 appeared to be on the surface of the same cell body, maintained or increased their brightness

28 after depolarization (Fig $8 \mathrm{H}$, black trace, peaks 2, 6, 7). These puncta could represent Kv2

29 proteins on a neighboring cell, internalized Kv2-GxTX-594 complexes, off-target labeling by

30 GxTX-594, or Kv2 proteins that are unresponsive to voltage. When the kinetics of fluorescence

31 intensity decay of individual voltage-sensitive puncta were fit with Eq. 1, $k_{\Delta F}$ values were similar 
1 between puncta (Fig $8 \mathrm{I}$ ), consistent with these spatially separated puncta all being on the surface

2 of the voltage-clamped neuron. The fluorescence changes measured in these puncta were similar

3 to those predicted by the Figure 6 model (Fig 8 I, blue line). To address whether the fluorescence

4 change at the cell membrane was driven by decreases in regions of punctate fluorescence, the

5 punctate and non-punctate fluorescence intensity changes were analyzed separately. The regions

6 with fluorescence intensities above average for the path (Fig $8 \mathrm{H}$, dashed line) were binned as

7 one group. The above-average group, by definition, contained all punctate fluorescence. When

8 comparing the fluorescence before and during the $0 \mathrm{mV}$ step, the regions that were initially

9 below average maintained the same intensity (103 $\pm 8 \%$ ); regions of above average fluorescence

10 decreased in the intensity $(70 \pm 8 \%$ ) (Fig $8 \mathrm{~J})$. This suggests that the detectable unlabeling along

11 the cell membrane originated in the Kv2-like puncta, not the regions of lower fluorescence

12 intensity between them.

14 To determine whether the dynamics of voltage-dependent response of GxTX-594 fluorescence

15 on neurons in brain slices were consistent with labeling of Kv2.1, we performed experiments

16 with Kv2.1-expressing CHO cells under similar conditions as brain slice: $100 \mathrm{nM} \mathrm{GxTX-594,}$

$1730^{\circ} \mathrm{C}, \mathrm{Cs}^{+}$-containing patch pipette solution. The rate of fluorescence changes in $\mathrm{Kv} 2.1-\mathrm{CHO}$

18 cells were similar to neurons in brain slices, and consistent with the $k_{\Delta F}$ of $0.06 \mathrm{~s}^{-1}$ predicted by

19 Figure 6 model (Fig $8 \mathrm{~K}$ ). The data indicate that the voltage sensors of Kv2 proteins in

20 hippocampal CA1 neurons have a similar response to voltage as the voltage-sensitive Kv2.1

21 proteins in $\mathrm{CHO}$ cells. 


\section{Discussion}

2 We conclude that GxTX-594 dynamically labels a resting conformation of endogenous Kv2

3 proteins in neurons. This conclusion is based on a series of findings: GxTX-594 labels Kv2

4 proteins (Fig 1) in the presence of its obligate neuronal auxiliary subunit AMIGO-1 (Fig 2), but

5 does not label related $\mathrm{Kv}$ proteins (Fig 6). Steps to $0 \mathrm{mV}$ resulted in dynamic unlabeling of CHO

6 cells (Fig 3) and neurons (Fig 8), with similar kinetics (Fig 8 K). The punctate GxTX-594

7 labeling of CA1 neurons is consistent with the patterns of endogenous Kv2 expression seen by

8 immunofluorescence (Misonou et al. 2005, Bishop et al. 2015, 2018), and Kv2.1-GFP

9 expression (Fig 7). These results are consistent with the GxTX-594 probe labeling endogenous

$10 \mathrm{Kv} 2$ in rat CA1 hippocampal pyramidal neurons and unlabeling in response to voltage activation.

11 This is an important result demonstrating that an EVAP approach can reveal conformational

12 changes of molecularly specified voltage sensor subtypes, in tissue, with subcellular resolution.

13 Below, we discuss scientific questions that could be addressed with GxTX-594, limitations of

14 GxTX-594, and the potential for engineering mechanistically related probes to report activity of

15 other endogenous proteins.

\section{Unique capabilities of GxTX-594}

18 The Kv2 EVAP presented here is the only imaging method we are aware of for measuring

19 voltage-sensitive conformational changes of a specific, endogenous protein. The molecular,

20 conformational, and spatial precision of fluorescence from GxTX-594 demonstrates its utility for

21 identifying where in tissue the conformational status of Kv2 voltage sensors becomes altered.

22 GxTX-594 labels the fully resting conformation of the Kv2 voltage sensor, in which the first

23 gating charge of the Kv2 S4 segment is expected to be in the gating charge transfer center (Tao

24 et al. 2010). Images of GxTX-594 fluorescence reveal this conformation's occurrence, with

25 subcellular spatial resolution. Importantly, the thermodynamic model we develop allows

26 deconvolution of the behavior of unlabeled Kv2 proteins from Kv2 proteins inhibited by GxTX-

27594.

29 Our results indicate that the majority of $\mathrm{Kv} 2$ protein clustered at an individual plasma

30 membrane-endoplasmic reticulum junction can be voltage sensitive. This consistent with an

31 earlier proposal that, in rat CA1 neurons, clustered Kv2.1 proteins remain voltage sensitive, but 
1 voltage sensing is decoupled from pore opening (Fox et al. 2013). Interestingly, when Kv2.1 is

2 overexpressed in CHO cells, a fraction of the Kv2.1-associated GxTX-594 fluorescence is

3 voltage insensitive (Fig 4C). This observation is consistent with voltage sensor immobilization in

4 some surface-expressed Kv2.1 proteins. A similar phenomenon has been noted with the L-type

$5 \mathrm{Ca}^{2+}$ channel Cav1.2, which has some gating charge immobilized until it is bound by an

6 intracellular protein (Turner et al. 2019).

8 We used images of GxTX-594 fluorescence to measure the coupling between endogenous Kv2

9 proteins and membrane potential at specific, subcellular anatomical locations. This demonstrates

10 that GxTX-594 enables measurement of coupling membrane voltage to Kv2 voltage sensor

11 conformational change. Furthermore, if other cellular perturbations are coupled to Kv2 voltage

12 sensors, they as well should affect GxTX-594 labeling. Thus, GxTX-594 imaging could enable

13 studies of a host of questions about the voltage sensitivity of the nonconducting functions of Kv2

14 proteins, including: formation of plasma membrane-endoplasmic reticulum junctions (Antonucci

15 et al. 2001, Fox et al. 2015, Kirmiz, Palacio et al. 2018), regulation of exocytosis (Singer-Lahat

16 et al. 2007, Feinshreiber et al. 2010), regulation of insulin secretion (X. Q. Dai et al. 2012),

17 interaction with kinases, phosphatases and SUMOylases (Misonou et al. 2004, Park et al. 2006,

18 X.-Q. Dai et al. 2009, Cerda \& Trimmer 2011, McCord \& Aizenman 2013), formation of

19 specialized subcellular calcium signaling domains (Vierra et al. 2019), and interactions with

20 astrocytic end feet (Du et al. 1998). Imaging GxTX-594 while perturbing any of these functions

21 could reveal coupling to Kv2 voltage sensors. Beyond the nervous system, Kv2 proteins are

22 coupled to a wide variety of physiological responses in organs throughout the body including

23 muscle, thymus, spleen, kidney, adrenal gland, pancreas, lung, and reproductive organs

24 (Bocksteins 2016). Imaging GxTX-594 with functional measurements from these tissues could

25 reveal how Kv2 proteins couple voltage changes to their many physiological outputs.

27 Limitations of $\mathbf{G x T X - 5 9 4}$

28 The selectivity for a specific conformation of the Kv2 target protein, and the spatial precision of

29 fluorescence from GxTX-594, appear to be near theoretical limits. However, the temporal

30 resolution of GxTX-594 is far slower than the kinetics of Kv2 conformational change, limiting

31 measurements to the probability, averaged over time, that voltage sensors are resting or active. 
1 The probability of a conformation's occurrence is a valuable measure, and the ultimate

2 quantitation of many biophysical studies of ion channels (e.g., open probability, steady state

3 conductance, gating charge-voltage relation). The kinetics of GxTX-594 labeling are compatible

4 with measuring changes in Kv2 activity on a time scale of tens of seconds. We have

5 demonstrated that the temporal resolution of GxTX-594 is compatible with live imaging and

6 electrophysiology experiments.

8 Fluorescence signal intensity limits interpretation of EVAP labeling. We found that the intensity

9 of GxTX-594 labeling of CA1 neurons was sufficient to report voltage sensing of their

10 endogenous Kv2 proteins. This result demonstrates that GxTX-594 labeling can be implemented

11 a tissue that expresses Kv2 proteins. Kv2 proteins are expressed by most neurons, and many non-

12 neuronal cell types throughout the body (Bocksteins 2016). We expect that GxTX-594 imaging

13 could be implemented in most brain regions. CA1 hippocampal neurons express Kv2 proteins at

14 a density typical of central neurons (Misonou et al. 2004, Vacher et al. 2008, Speca et al. 2014).

15 In other cell types, such as neurons of the subiculum, or the inner segment of photoreceptors,

16 Kv2 proteins are expressed at far higher densities (Maletic-Savatic et al. 1995, Gayet-Primo et

17 al. 2018). Improved signal to noise would be expected from such cells that express higher

18 densities of Kv2 proteins.

20 GxTX-based probes inhibit the Kv2 proteins they label. Thus, GxTX-594 depletes the population 21 of Kv2 proteins responding normally to physiological stimuli. While the concentration of an

22 EVAP can be lowered to minimize interference with Kv2 activity, fluorescence intensity is

23 diminished and further limits the ability to detect subtle physiological changes. With a related

24 probe, we explored the impact of simultaneously decreasing toxin concentration and stimulating

25 with physiological stimuli (Tilley et al. 2014). Here, we demonstrate that lower concentration

26 and physiological stimuli are not always required for scientifically meaningful implementation of

27 the probe. Even when using GxTX-594 concentrations that grossly interfere with activity, the

28 behavior of unlabeled Kv2 proteins can be calculated using thermodynamic model we have

29 developed. 
1 A limitation of the analysis developed here is that the model of Kv2 voltage sensor

2 conformational change is an oversimplification. The gating dynamics of Kv2 channels are more

3 complex than our model (Islas \& Sigworth 1999, Scholle et al. 2004, Jara-Oseguera et al. 2011,

4 Tilley et al. 2019). Under some conditions the assumption of voltage sensor independence may

5 limit the model's predictive power. Additionally, the model of GxTX-594 labeling developed here assumes that voltage sensors are in continuous equilibrium. These deviations from

7 equilibrium could explain the deviation of the model from the data in response to high frequency

8 voltage steps (Fig 4 C, D).

Conformation-selective probes reveal conformational change of endogenous proteins

11 Measurements of dynamic labeling by a conformation-selective probe such as GxTX can enable

12 deduction of how unlabeled proteins behave. This is perhaps counterintuitive because GxTX

13 inhibits voltage sensor movement of the Kv2 protein it binds, and thus only the bound protein

14 generate optical signals (Tilley et al. 2014, 2019). This approach is analogous to calcium

15 imaging experiments, which have been spectacularly informative about physiological calcium

16 signaling (W. Yang \& Yuste 2017), despite the fact that no optical signals originate from the

17 physiologically relevant free $\mathrm{Ca}^{2+}$, only from $\mathrm{Ca}^{2+}$ that is chelated by a dye. In all such

18 experiments, fluorescence from $\mathrm{Ca}^{2+}$-bound dyes is deconvolved using the statistical

19 thermodynamics of $\mathrm{Ca}^{2+}$ binding to calculate free $\mathrm{Ca}^{2+}$ (Adams 2010). Similarly, GxTX-based

20 probes dynamically bind to unlabeled Kv2 proteins, and the binding rate is dependent on the

21 probability that unlabeled voltage sensors are in a resting conformation (Fig 5). Thus, the

22 conformations of unlabeled Kv2 proteins influence the dynamics of labeling with GxTX-based

23 probes. Consequently, the dynamics of labeling reveal the conformations of unlabeled Kv2

24 proteins.

26 Deployment of GxTX-594 to report conformational changes of endogenous proteins

27 demonstrates that conformation-selective ligands can be used to image occurrence of the

28 conformations they bind to. The same principles of action apply to any conformation-selective

29 labeling reagent, suggesting that probes for conformational changes of many different proteins

30 could be developed. Probes could conceivably be developed from the many other voltage sensor

31 toxins and other gating modifiers that act by a similar mechanism as GxTX, yet target the 
1 voltage sensors of different ion channel proteins (McDonough et al. 1997, Sack et al. 2004,

2 Catterall et al. 2007, Swartz 2007, Schmalhofer et al. 2008, Peretz et al. 2010, McCormack et al.

3 2013, Ahuja et al. 2015, A. H. Zhang et al. 2018, Dockendorff et al. 2018). Conformation-

4 selective binders have been engineered for a variety of other proteins, and methods to quantify

5 conformational changes from their fluorescence are needed. For example, fluorescently-labeled

6 conformation-selective binders have revealed that endocytosed GPCRs continue to remain in a

7 physiologically activated conformation (Irannejad et al. 2013, Tsvetanova et al. 2015, Eichel \&

8 von Zastrow 2018). A means to determine the conformational equilibria of GPCRs from

9 fluorescence images has not yet been developed. We suggest that the statistical thermodynamic

10 framework developed here could provide a starting point for more quantitative interpretation of

11 other conformation-selective molecular probes. 


\section{Materials and methods}

1 GxTX-594 synthesis

2 The Ser13Cys GxTX peptide synthesized as described (Tilley et al. 2014). Methionine 35 of

3 GxTX was replaced by the oxidation-resistant noncanonical amino acid norleucine and serine 13

4 was replaced with cysteine to create a spinster thiol. Ser13Cys GxTX was labeled with a Texas

5 red derivative (Alexa Fluor 594 C $_{5}$ maleimide, Thermo Fisher Scientific, Catalog \# 10256).

6 Ser13Cys GxTX lyophilisate was brought to $560 \mu \mathrm{M}$ in 50\% ACN $+1 \mathrm{mM} \mathrm{Na} 2 \mathrm{EDTA}$. $2.4 \mu \mathrm{L}$

7 of $1 \mathrm{M}$ Tris (pH 6.8 with $\mathrm{HCl}$ ), $4 \mu \mathrm{L}$ of $10 \mathrm{mM}$ of Alexa Fluor $594 \mathrm{C}_{5}$ maleimide in DMSO and

$8 \quad 17.9 \mu \mathrm{L}$ of $560 \mu \mathrm{M}$ Ser13Cys GxTX were added for a final solution of $100 \mathrm{mM}$ Tris, $1.6 \mathrm{mM}$

9 Alexa Fluor $594 \mathrm{C}_{5}$ maleimide and $0.4 \mathrm{mM} \mathrm{GxTX}$ in $24 \mu \mathrm{L}$ of reaction solution. Reactants were

10 combined in a $1.5 \mathrm{~mL}$ low protein binding polypropylene tube (LoBind, Eppendorf, Catalog \#

11022431081 ) and mixed at $1000 \mathrm{RPM}, 20^{\circ} \mathrm{C}$ for 4 hours (Thermomixer $5355 \mathrm{R}$, Eppendorf).

12 After incubation, the tube was centrifuged at $845 \mathrm{RCF}$ for 10 minutes at room temperature. A

13 purple pellet was observed post-centrifugation. The supernatant was transferred to a fresh tube

14 and centrifuged at $845 \mathrm{RCF}$ for 10 minutes. After this $2^{\text {nd }}$ centrifugation, no visible pellet was

15 seen. The supernatant was injected onto a reverse-phase HPLC $\mathrm{C}_{18}$ column (Biobasic- 4.6mm

$16 \mathrm{RP}_{-} \mathrm{C}_{18} 5 \mu \mathrm{m}$, Thermo Fisher Scientific, Catalog \# 2105-154630) equilibrated in 20\% ACN,

$170.1 \%$ TFA at $1 \mathrm{~mL} / \mathrm{min}$ and eluted with a protocol holding in $20 \% \mathrm{ACN}$ for 2 minutes,

18 increasing to $30 \% \mathrm{ACN}$ over 1 minute, then increasing $\mathrm{ACN}$ at $0.31 \%$ per minute. HPLC

19 effluent was monitored by fluorescence and an absorbance array detector. $1 \mathrm{ml}$ fractions were

20 pooled based on fluorescence (280 $\mathrm{nm}$ excitation, $350 \mathrm{~nm}$ emission) and absorbance (214 $\mathrm{nm}$,

$21280 \mathrm{~nm}$, and $594 \mathrm{~nm}$ ). GxTX-594 peptide-fluorophore conjugate eluted at approximately 35\%

22 ACN, and mass was confirmed by mass spectrometry using a Bruker UltraFlextreme MALDI-

23 TOF/TOF (Fig 1 Supplement 1). Samples for identification from HPLC eluant were mixed 1:1 in

24 an aqueous solution of $25 \% \mathrm{MeOH}$ and $0.05 \%$ TFA saturated with alpha-cyano-4-hydrocinnamic

25 acid, pipetted onto a ground-steel plate, dried under vacuum, and ionized with 60-80\% laser

26 power. Molecular species were detected using a reflector mode protocol and quantitated using

27 Bruker Daltonics flexAnalysis 3.4. Lyophilizate containing GxTX-594 conjugation product was

28 dissolved in CE buffer (defined below), and stored at $-80^{\circ} \mathrm{C}$. GxTX-594 concentration was

29 determined by $280 \mathrm{~nm}$ absorbance using a calculated extinction coefficient of 18,900 A.U. M-1

$30 \mathrm{~cm}^{-1}$. 
2 CHO cell methods

3 CHO cell culture and transfection

4 The CHO-K1 cell line (ATCC) and a subclone transfected with a tetracycline-inducible rat

$5 \quad$ Kv2.1 construct (Kv2.1-CHO) (Trapani \& Korn 2003), were cultured as described previously

6 (Tilley et al. 2014). To induce Kv2.1 expression in Kv2.1-TREx-CHO cells, $1 \mu \mathrm{g} / \mathrm{mL}$

7 minocycline (Enzo Life Sciences, Catalog \# ALX-380-109-M050), prepared in 70\% ethanol at 2

$8 \mathrm{mg} / \mathrm{mL}$, was added to the maintenance media to induce $\mathrm{K}^{+}$expression. Minocycline was added

9 40-48 hours before imaging and voltage clamp fluorometry experiments. Transfections were

10 achieved with Lipofectamine 2000 (Life Technologies, Catalog \# 1668027). $1.1 \mu \mathrm{L}$ of

11 Lipofectamine was diluted, mixed, and incubated in $110 \mu \mathrm{L}$ of Opti-MEM (Gibco, Product

12 Number 31985-062, Lot Number 1917064) in a 1:100 ratio for 5 minutes at room temperature.

13 Concurrently, $1 \mu \mathrm{g}$ of plasmid DNA and $110 \mu \mathrm{L}$ of Opti-MEM were mixed in the same fashion.

14 DNA and Lipofectamine 2000 mixtures were combined, titurated, and let sit for 20 minutes.

15 Then, the transfection cocktail mixture was added to a $35 \mathrm{~mm}$ cell culture dish of CHO cells at 16 approximately $40 \%$ confluency and allowed to settle at $37^{\circ} \mathrm{C} 5 \% \mathrm{CO}_{2}$ for $4-6$ hours before the 17 media was replaced. Rat Kv2.1-GFP (Antonucci et al. 2001), rat Kv2.2-GFP (Kirmiz, Vierra et 18 al. 2018), rat Kv1.5-GFP (Li et al. 2001), rat Kv4.2-GFP (Shibata et al. 2003), mouse BK-GFP

19 (Trimmer Lab, UC Davis), rat Kv2.1 S586A-GFP (Kirmiz, Palacio et al. 2018), rat AMIGO-

20 YFP (Bishop et al. 2015), rat KvBeta2 (Shibata et al. 2003) and rat KCHiP2 (An et al. 2000)

21 plasmids were all kind gifts from James Trimmer, University of California, Davis. Identities of

22 constructs were confirmed by sequencing from their CMV promoter.

24 Confocal and Airy disk imaging

25 Confocal images were obtained with an inverted confocal system (Zeiss LSM 880 410900-247-

26 075) run by ZEN black v2.1. A 63x/1.40 NA Oil DIC objective (Zeiss 420782-9900-799) was

27 used for most imaging experiments; a 63x/1.2 NA Water DIC objective (Zeiss 441777-9970-

28 000) was used for voltage clamp fluorometry experiments. GFP and YFP were excited with the

$29488 \mathrm{~nm}$ line from an argon laser $(3.2 \mathrm{~mW}$ at installation) powered at $0.5 \%$ unless otherwise

30 noted. GxTX594 was excited with $594 \mathrm{~nm}$ helium-neon laser (0.6 mW at installation) powered at

$31 \quad 10 \%$ unless otherwise noted. WGA-405 was excited with a $405 \mathrm{~nm}$ diode laser, $(3.5 \mathrm{~mW}$ at 
1 installation) powered at $1 \%$ unless otherwise noted. Temperature inside the microscope housing

2 was $27-30^{\circ} \mathrm{C}$.

4 In confocal imaging mode, fluorescence was collected with the microscope's 32-detector gallium

5 arsenide phosphide detector array arranged with a diffraction grating to measure 400-700 nm

6 emissions in $9.6 \mathrm{~nm}$ bins. Emission bands were 495-550 nm for GFP and YFP, 605-700 nm for

7 GxTX-594, and 420-480 nm for WGA-405. Point spread functions were calculated using ZEN

8 black software using emissions from $0.1 \mu \mathrm{m}$ fluorescent microspheres, prepared on a slide

9 according to manufacturer's instructions (Thermo Fisher Scientific, Catalog \# T7279). The point

10 spread functions for confocal images with the $63 \mathrm{x} / 1.40$ Oil DIC objective in the X-Y direction

11 were $228 \mathrm{~nm}$ (488 nm excitation) and $316 \mathrm{~nm}$ (594 nm excitation).

13 In Airy disk imaging mode, fluorescence was collected with the microscope's 32-detector

14 gallium arsenide phosphide detector array arranged in a concentric hexagonal pattern (Zeiss

15 Airyscan 410900-2058-580). After deconvolution, the point spread functions for the $63 \mathrm{x} / 1.40$

16 NA objective with $488 \mathrm{~nm}$ excitation was $124 \mathrm{~nm}$ in X-Y and $216 \mathrm{~nm}$ in Z; with $594 \mathrm{~nm}$

17 excitation $168 \mathrm{~nm}$ in $\mathrm{X}-\mathrm{Y}$ and $212 \mathrm{~nm}$ in Z. For the 63x/1.2 NA objective, the point spread

18 function with $488 \mathrm{~nm}$ excitation was $187 \mathrm{~nm}$ in $\mathrm{X}-\mathrm{Y}$ and $214 \mathrm{~nm}$ in $\mathrm{Z}$; the point spread function

19 with $594 \mathrm{~nm}$ excitation was $210 \mathrm{~nm}$ in X-Y and $213 \mathrm{~nm}$ in Z.

21 Unless stated otherwise, cells were plated in uncoated $35 \mathrm{~mm}$ dishes with a $7 \mathrm{~mm}$ inset No. 1.5

22 coverslip (MatTek, Catalog \# P35G-1.5-20-C). The CHO cell external (CE) solution used for

23 imaging and electrophysiology contained (in mM): $3.5 \mathrm{KCl}, 155 \mathrm{NaCl}, 10 \mathrm{HEPES}, 1.5 \mathrm{CaCl}_{2}, 1$

$24 \mathrm{MgCl}_{2}$, adjusted to $\mathrm{pH} 7.4$ with $\mathrm{NaOH}$. Measured osmolarity was $315 \mathrm{mOsm}$. When noted,

25 solution was supplemented with either $10 \mathrm{mM}$ glucose (CEG) or $10 \mathrm{mM}$ glucose and 1\% BSA

26 (CEGB).

28 For time-lapse, GxTX-594 dose-response experiments, Kv2.1-CHO cells were plated onto 22 x

$2922 \mathrm{~mm}$ No. 1.5H coverglass (Deckglaser). Prior to imaging, cell maintenance media was

30 removed and replaced with CEGB, then coverslip was mounted on an imaging chamber (Warner

31 Instrument, Catalog \# RC-24E) with vacuum grease. During time-lapse imaging, indicated 
1 concentrations of GxTX-594 were applied for 10 minutes followed by manual wash-out with

2 CEGB solution. 15 minutes after wash-out, the next GxTX-594 concentration was added.

3 Solutions were added to the imaging chamber perfusion via a syringe at a flow rate of $\sim 1 \mathrm{~mL} /$

$410 \mathrm{sec}$. Images were taken every $5 \mathrm{sec}$. Laser power was set to $0.5 \%$ for the $488 \mathrm{~nm}$ laser and

$5 \quad 1.5 \%$ for the $594 \mathrm{~nm}$ laser. For colocalization experiments with GFP-tagged proteins, cells were incubated in $100 \mathrm{nM}$ GxTX-594 for 5 minutes and then washed with CEGB before imaging.

8 Whole cell voltage clamp for $\mathrm{CHO}$ cell imaging

9 Kv2.1-TREx-CHO cells plated in glass-bottom $35 \mathrm{~mm}$ dishes were washed with CEGB, placed

10 in the microscope, and then incubated in $100 \mu \mathrm{L}$ of $100 \mathrm{nM}$ GxTX594 for 5 minutes to label

11 cells. Before patch clamp, the solution was diluted with $1 \mathrm{~mL}$ of CEG for a working

12 concentration of 9 nM GxTX594 during experiments. Cells with obvious GxTX-594 surface

13 staining were voltage-clamped in whole-cell mode with an EPC-10 patch clamp amplifier

14 (HEKA) run by Patchmaster software, v2x90.2 (HEKA). The patch pipette contained a

15 potassium-deficient $\mathrm{Cs}^{+}$internal pipette solution to limit outward current and reduce voltage

16 error: $70 \mathrm{mM} \mathrm{CsCl}, 50 \mathrm{mM} \mathrm{CsF}, 35 \mathrm{mM} \mathrm{NaCl}, 1 \mathrm{mM}$ EGTA, $10 \mathrm{mM}$ HEPES, brought to $\mathrm{pH} 7.4$

17 with $\mathrm{CsOH}$. Osmolarity was $310 \mathrm{mOsm}$. The liquid junction potential was calculated to be 3.5

$18 \mathrm{mV}$ and was not corrected. Borosilicate glass pipettes (Sutter Instruments, Catalog \# BF 150-

$19110-10 \mathrm{HP}$ ) were pulled with blunt tips to resistances less than $3.0 \mathrm{M} \Omega$ in these solutions. Cells

20 were held at $-80 \mathrm{mV}$ (unless noted otherwise) and stepped to indicated voltages. The voltage step

21 stimulus was maintained until any observed change in fluorescence was complete. For stimulus-

22 frequency dependence experiments, cells were given $2 \mathrm{~ms}$ steps to $40 \mathrm{mV}$ at stated frequencies

$23(0.02,5,10,20,50,100,150$, or $200 \mathrm{~Hz})$. Images for voltage clamp fluorometry were taken in

24 Airy disk imaging mode with the settings described above.

Whole cell voltage clamp for $\mathrm{CHO}$ cell $\mathrm{K}^{+}$current recordings

27 Whole-cell voltage clamp was used to measure currents from CHO cells expressing Kv2.1-GFP,

$28 \mathrm{Kv}$ 2.2-GFP, Kv1.5-GFP, Kv4.2-GFP, BK-GFP or GFP that we transfected as described above.

29 Cells were plated on glass bottom dishes. Cells were held at $-80 \mathrm{mV}$, then $100 \mathrm{~ms}$ voltage steps

30 were delivered ranging from $-80 \mathrm{mV}$ to $+80 \mathrm{mV}$ in $+5 \mathrm{mV}$ increments. Pulses were repeated

31 every 2 seconds. The external (bath) solution contained CE solution. The internal (pipette) 
1 solution contained (in $\mathrm{mM}$ ): $35 \mathrm{KOH}, 70 \mathrm{KCl}, 50 \mathrm{KF}, 50 \mathrm{HEPES}, 5$ EGTA adjusted to $\mathrm{pH} 7.2$

2 with $\mathrm{KOH}$. Liquid junction potential was calculated to be $7.8 \mathrm{mV}$ and was not corrected.

3 Borosilicate glass pipettes (Sutter Instruments, Cat \# BF150-110-10HP) were pulled into pipettes

4 with resistance less than $3 \mathrm{M} \Omega$ for patch clamp recording. Recordings were at room temperature

$5 \quad\left(22-24^{\circ} \mathrm{C}\right)$. Voltage clamp was achieved with an Axon Axopatch 200B amplifier (MDS

6 Analytical Technologies) run by Pachmaster software, v2x90.2 (HEKA). Holding potential was

$7 \quad-80 \mathrm{mV}$. Capacitance and Ohmic leak were subtracted using a P/5 protocol. Recordings were low

8 pass filtered at $10 \mathrm{kHz}$ and digitized at $100 \mathrm{kHz}$. Voltage clamp data were analyzed and plotted

9 with Igor Pro 7 or 8 (Wavemetrics). Current amplitudes at each voltage were the average from

$10 \quad 0.19-0.20 \mathrm{~s}$ after voltage step. As the experiments plotted in Figure 6 Supplement 1 A were

11 merely to confirm functional expression of ion channels at the cell surface, series resistance

12 compensation was not used and substantial cell voltage errors are predicted during these

13 experiments.

\section{Brain slice methods}

16 Hippocampal slice culture preparation and transfection

17 All experimental procedures were approved by the University of California Davis Institutional

18 Animal Care and Use Committee and were performed in strict accordance with the Guide for the

19 Care and Use of Laboratory Animals of the NIH. Animals were maintained under standard light-

20 dark cycles and had ad libitum access to food and water. Organotypic hippocampal slice cultures

21 were prepared from postnatal day 5-7 rats, as described (Stoppini et al. 1991) and detailed in a

22 video protocol (Opitz-Araya \& Barria 2011). DIV15-30 neurons were transfected 2-6 days

23 before imaging via biolistic gene transfer (160 psi, Helios gene gun, Bio-Rad), as described in a

24 detailed video protocol (Woods \& Zito 2008). $10 \mu \mathrm{g}$ of plasmid was coated to 6-8 $\mathrm{mg}$ of $1.6 \mu \mathrm{m}$

25 gold beads.

\section{Two-photon excitation slice imaging}

28 Image stacks (512 x 512 pixels, $1 \mathrm{~mm}$ Z-steps; $0.035 \mu \mathrm{m} / \mathrm{pixel})$ were acquired using a custom

29 two-photon excitation microscope (Olympus LUMPLFLN 60XW/IR2 objective, 60x, 1.0 NA)

30 with two pulsed Ti:sapphire lasers (Mai Tai: Spectra Physics) tuned to $810 \mathrm{~nm}$ (for GxTX-594

31 imaging) and $930 \mathrm{~nm}$ (for GFP imaging) and controlled with ScanImage (Pologruto et al. 2003). 
1 After identifying a neuron expressing Kv2.1-GFP, perfusion was stopped and GxTX-594 was

2 added to the static bath solution to a final concentration of $100 \mathrm{nM}$. After five minutes

3 incubation, perfusion was restarted, leading to wash-out of GxTX-594 from the slice bath. Red

4 and green photons (Chroma: 565dcxr, BG-22 glass, HQ607/45) emitted from the sample were

5 collected with two sets of photomultiplier tubes (Hamamatsu R3896).

\section{Whole cell voltage clamp for brain slice imaging}

8 Organotypic hippocampal slice cultures (DIV 6-7, not transfected) were transferred to an

9 imaging chamber with recirculating ACSF maintained at $30^{\circ} \mathrm{C}$. To hold the slice to the bottom of

10 the chamber, a horseshoe-shaped piece of gold wire was used to weight the membrane holding

11 the slice. ACSF contained (in $\mathrm{mM}$ ) $127 \mathrm{NaCl}, 25 \mathrm{NaHCO}_{3}, 25 \mathrm{D}$-glucose, $2.5 \mathrm{KCl}, 1.25$

$12 \mathrm{NaH}_{2} \mathrm{PO}_{4}, 1 \mathrm{MgCl} 2,2 \mathrm{CaCl}_{2}, 200 \mathrm{nM}$ tetrodotoxin, $\mathrm{pH} 7.3$ and aerated with 95\% $\mathrm{O}_{2} / 5 \% \mathrm{CO}_{2}$

13 ( $310 \mathrm{mOsm}) .4 \mathrm{~mL}$ of $100 \mathrm{nM}$ GxTX-594 in ACSF were used in the circulating bath to allow

14 the toxin to reach the slice and reach the desired concentration of $100 \mathrm{nM}$ throughout the

15 circulating bath. Images were acquired beginning 3 minutes after GxTX-594 was added.

16 Apparent CA1 neurons with GxTX-594 labeling in a Kv2-like pattern were selected for whole-

17 cell patch clamp. Voltage clamp was achieved using an Axopatch 200B amplifier (Axon

18 Instruments) controlled with custom software written in Matlab (MathWorks, Inc.). Patch

19 pipettes (5-7 M $\Omega$ ) were filled with intracellular solution containing (in $\mathrm{mM})$ : $135 \mathrm{Cs}-$

20 methanesulfonate, $10 \mathrm{Na}_{2}$-phosphocreatine, $3 \mathrm{Na}$-L-ascorbate, $4 \mathrm{NaCl}, 10 \mathrm{HEPES}, 4 \mathrm{MgCl}_{2}, 4$

$21 \mathrm{Na} 2 \mathrm{ATP}, 0.4 \mathrm{NaGTP}, \mathrm{pH}$ 7.2. Neurons were clamped at $-70 \mathrm{mV}$. Input resistance and holding

22 current were monitored throughout the experiment. Cells were excluded if the pipette series

23 resistance was higher than $25 \mathrm{M} \Omega$ or if the holding current exceeded -100 pA. To activate Kv2

24 channels, a $50 \mathrm{~s}$ depolarizing step from $-70 \mathrm{mV}$ to $0 \mathrm{mV}$ was given.

\section{Image analysis}

27 Fluorescence images were analyzed using ImageJ 1.52n software (C. A. Schneider et al. 2012).

28 Regions of interest (ROIs) encompassed the entire fluorescent region of an individual cell or

29 neuron, unless mentioned otherwise. ROIs were drawn manually. Analysis of images was

30 conducted independently by multiple researchers who produced similar results, but analysis was

31 not conducted in a blinded nor randomized fashion. Fluorescence intensity $(F)$ was background 
1 subtracted using mean $\mathrm{F}$ of a region lacking cells. For $F / F_{\text {init }}$ normalization, $F_{\text {init }}$ was the mean

2 fluorescence preceding the indicated voltage stimuli, or the max observed intensity in dose

3 response experiments. Further details of specific normalization procedures are provided in figure

4 legends. Time dependence of fluorescence intensity was fit with a monoexponential decay (Eq.

5 1). For colocalization analyses the Pearson coefficient was calculated using the JACoP plugin

6 (Bolte \& Cordelières 2006). Colocalization analyses were conducted within ROIs defining

7 individual cells. Plotting and curve fitting was performed with with Igor Pro 7 or 8

8 (Wavemetrics), which performs nonlinear least-squares fits using a Levenberg-Marquardt

9 algorithm. Sample sizes of $n \geq 3$ were selected to confirm reproducibility. Sample sizes of $n \geq 6$

10 were selected to power nonparametric statistical comparisons to discern $p<0.01$. Error values

11 from individual curve fittings are standard deviations. All other errors, including error bars,

12 indicate standard errors. Arithmetic means are reported for intensity measurements and

13 correlation coefficients. Geometric means are reported for time constants and rates. As the

14 distributions underlying variability in results are unknown, nonparametric statistical comparisons

15 were conducted with Mann-Whitney $U$ tests and two-tailed $p$ values reported individually if $p>$

160.0001.

18 Model calculations

19 Predictions of the Scheme I and II models were calculated using Microsoft Excel. A spreadsheet

20 containing model calculations that can be used to generate model prediction is included as a

21 supplement (Model Calculation Supplement). 


\section{Acknowledgements}

We thank James Trimmer (University of California, Davis) for numerous discussions, and constructive critical reading of an early version of the manuscript. We thank Georgeann Sack (Afferent, LLC) for critical reading, editing, and feedback. This research was supported by US National Institutes of Health grants R01NS096317 (B.E.C. and J.T.S.), U01NS090581, R21EY026449, and T32GM007377. P. Thapa was supported by American Heart Association postdoctoral fellowship 17POST33670698. Work at the Molecular Foundry was supported by the Director, Office of Science, Office of Basic Energy Sciences, Division of Materials Sciences and Engineering, of the U.S. Department of Energy under Contract No. DE-AC02-05CH11231. The authors declare no competing financial interests. 


\section{Author contributions (CRediT nomenclature)}

Parashar Thapa: Conceptualization, Formal analysis, Investigation, Methodology, Visualization, Writing- original draft, Writing- reviewing \& editing

Robert Stewart: Conceptualization, Formal analysis, Investigation, Methodology, Visualization, Writing- original draft, Writing- reviewing \& editing

Rebecka J. Sepela: Conceptualization, Formal analysis, Investigation, Methodology, Visualization, Writing- original draft, Writing- reviewing \& editing

Oscar Vivas: Investigation, Methodology, Writing- reviewing \& editing

Laxmi K. Parajuli: Investigation, Methodology, Writing- reviewing \& editing

Mark Lillya: Conceptualization, Formal analysis, Investigation, Methodology, Visualization

Sebastian Fletcher-Taylor: Investigation, Methodology, Writing- reviewing \& editing

Bruce E. Cohen: Conceptualization, Funding acquisition, Project administration, Supervision, Writing- reviewing \& editing

Karen Zito: Conceptualization, Funding acquisition, Investigation, Methodology, Project administration, Supervision, Writing- original draft, Writing- reviewing \& editing

Jon T. Sack: Conceptualization, Formal analysis, Funding acquisition, Investigation, Methodology, Project administration, Supervision, Visualization, Writing- original draft, Writing- reviewing \& editing 


\section{References}

Adams, S.R. (2010) How calcium indicators work. Cold Spring Harbor Protocols, 2010, pdb.top70. doi:10.1101/pdb.top70

Aggarwal, S.K. \& MacKinnon, R. (1996) Contribution of the S4 segment to gating charge in the Shaker K+ channel. Neuron, 16, 1169-77. doi:10.1016/S0896-6273(00)80143-9

Ahuja, S., Mukund, S., Deng, L., Khakh, K., Chang, E., Ho, H., Shriver, S., Young, C., Lin, S., Johnson, J.P., Wu, P., Li, J., Coons, M., Tam, C., Brillantes, B., Sampang, H., Mortara, K., Bowman, K.K., et al. (2015) Structural basis of Nav1.7 inhibition by an isoform-selective small-molecule antagonist. Science, 350, aac5464. doi:10.1126/science.aac5464

Amberg, G.C. \& Santana, L.F. (2006) Kv2 channels oppose myogenic constriction of rat cerebral arteries. American Journal of Physiology. Cell Physiology, 291, C348-56. doi:10.1152/ajpcell.00086.2006

An, W.F., Bowlby, M.R., Betty, M., Cao, J., Ling, H.P., Mendoza, G., Hinson, J.W., Mattsson, K.I., Strassle, B.W., Trimmer, J.S. \& Rhodes, K.J. (2000) Modulation of A-type potassium channels by a family of calcium sensors. Nature, 403, 553-556. doi:10.1038/35000592

Antonucci, D.E., Lim, S.T., Vassanelli, S. \& Trimmer, J.S. (2001) Dynamic localization and clustering of dendritic Kv2.1 voltage-dependent potassium channels in developing hippocampal neurons. Neuroscience, 108, 69-81. doi:10.1016/S0306-4522(01)00476-6

Armstrong, C.M. \& Bezanilla, F. (1973) Currents related to movement of the gating particles of the sodium channels. Nature, 242, 459-61. doi:10.1038/242459a0

Benndorf, K., Koopmann, R., Lorra, C. \& Pongs, O. (1994) Gating and conductance properties of a human delayed rectifier $\mathrm{K}+$ channel expressed in frog oocytes. The Journal of Physiology, 477, 1-14, John Wiley \& Sons, Ltd (10.1111). doi:10.1113/jphysiol.1994.sp020166

Bezanilla, F. (2008, April) How membrane proteins sense voltage. Nature Reviews Molecular Cell Biology, Nature Publishing Group. doi:10.1038/nrm2376

Bezanilla, F. (2018) Gating currents. The Journal of General Physiology, 150, 911-932. doi:10.1085/jgp.201812090

Bishop, H.I., Cobb, M.M., Kirmiz, M., Parajuli, L.K., Mandikian, D., Philp, A.M., Melnik, M., Kuja-Panula, J., Rauvala, H., Shigemoto, R., Murray, K.D. \& Trimmer, J.S. (2018) Kv2 Ion Channels Determine the Expression and Localization of the Associated AMIGO-1 Cell Adhesion Molecule in Adult Brain Neurons. Frontiers in Molecular Neuroscience, 11, 1. doi:10.3389/fnmol.2018.00001

Bishop, H.I., Guan, D., Bocksteins, E., Parajuli, L.K., Murray, K.D., Cobb, M.M., Misonou, H., Zito, K., Foehring, R.C. \& Trimmer, J.S. (2015) Distinct Cell- and Layer-Specific Expression Patterns and Independent Regulation of Kv2 Channel Subtypes in Cortical Pyramidal Neurons. The Journal of Neuroscience, 35, 14922-42. doi:10.1523/JNEUROSCI.1897-15.2015

Bocksteins, E. (2016) Kv5, Kv6, Kv8, and Kv9 subunits: No simple silent bystanders. The Journal of General Physiology, 147, 105-25. doi:10.1085/jgp.201511507

Bolte, S. \& Cordelières, F.P. (2006) A guided tour into subcellular colocalization analysis in light microscopy. Journal of Microscopy, 224, 213-32. doi:10.1111/j.13652818.2006.01706.x

Catterall, W.A., Cestèle, S., Yarov-Yarovoy, V., Yu, F.H., Konoki, K. \& Scheuer, T. (2007) Voltage-gated ion channels and gating modifier toxins. Toxicon, 49, 124-141. doi:10.1016/j.toxicon.2006.09.022 
Cerda, O. \& Trimmer, J.S. (2011) Activity-dependent phosphorylation of neuronal Kv2.1 potassium channels by CDK5. The Journal of Biological Chemistry, 286, 28738-48. doi:10.1074/jbc.M111.251942

Cobb, M.M., Austin, D.C., Sack, J.T. \& Trimmer, J.S. (2015) Cell Cycle-dependent Changes in Localization and Phosphorylation of the Plasma Membrane Kv2.1 K+ Channel Impact Endoplasmic Reticulum Membrane Contact Sites in COS-1 Cells. The Journal of Biological Chemistry, 290, 29189-201. doi:10.1074/jbc.M115.690198

Dai, X.Q., Kolic, J., Marchi, P., Sipione, S. \& Macdonald, P.E. (2009) SUMOylation regulates Kv2.1 and modulates pancreatic beta-cell excitability. Journal of Cell Science, 122, 775-9. doi: $10.1242 /$ jcs. 036632

Dai, X.Q., Manning Fox, J.E., Chikvashvili, D., Casimir, M., Plummer, G., Hajmrle, C., Spigelman, A.. F., Kin, T., Singer-Lahat, D., Kang, Y., Shapiro, A.. M.J., Gaisano, H.Y., Lotan, I. \& Macdonald, P.E. (2012) The voltage-dependent potassium channel subunit Kv2.1 regulates insulin secretion from rodent and human islets independently of its electrical function. Diabetologia, 55, 1709-20. doi:10.1007/s00125-012-2512-6

Dockendorff, C., Gandhi, D.M., Kimball, I.H., Eum, K.S., Rusinova, R., Ingólfsson, H.I., Kapoor, R., Peyear, T., Dodge, M.W., Martin, S.F., Aldrich, R.W., Andersen, O.S. \& Sack, J.T. (2018) Synthetic Analogues of the Snail Toxin 6-Bromo-2-mercaptotryptamine Dimer (BrMT) Reveal That Lipid Bilayer Perturbation Does Not Underlie Its Modulation of Voltage-Gated Potassium Channels. Biochemistry, 57, 2733-2743. doi:10.1021/acs.biochem.8b00292

Du, J., Haak, L.L., Phillips-Tansey, E., Russell, J.T. \& McBain, C.J. (2000) Frequencydependent regulation of rat hippocampal somato-dendritic excitability by the $\mathrm{K}+$ channel subunit Kv2.1. The Journal of Physiology, 522 Pt 1, 19-31. doi:10.1111/j.14697793.2000.t01-2-00019.xm

Du, J., Tao-Cheng, J.-H., Zerfas, P. \& McBain, C.J. (1998) The K+ channel, Kv2.1, is apposed to astrocytic processes and is associated with inhibitory postsynaptic membranes in hippocampal and cortical principal neurons and inhibitory interneurons. Neuroscience, $\mathbf{8 4}$, 37-48. doi:10.1016/S0306-4522(97)00519-8

Eichel, K. \& Zastrow, M. von. (2018) Subcellular Organization of GPCR Signaling. Trends in Pharmacological Sciences, 39, 200-208. doi:10.1016/j.tips.2017.11.009

Feinshreiber, L., Singer-Lahat, D., Friedrich, R., Matti, U., Sheinin, A., Yizhar, O., Nachman, R., Chikvashvili, D., Rettig, J., Ashery, U. \& Lotan, I. (2010) Non-conducting function of the Kv2.1 channel enables it to recruit vesicles for release in neuroendocrine and nerve cells. Journal of Cell Science, 123, 1940-1947. doi:10.1242/jcs.063719

Fox, P.D., Haberkorn, C.J., Akin, E.J., Seel, P.J., Krapf, D. \& Tamkun, M.M. (2015) Induction of stable ER-plasma-membrane junctions by Kv2.1 potassium channels. Journal of Cell Science, 128, 2096-105. doi:10.1242/jcs.166009

Fox, P.D., Loftus, R.J. \& Tamkun, M.M. (2013) Regulation of Kv2.1 K(+) conductance by cell surface channel density. The Journal of Neuroscience, 33, 1259-70. doi:10.1523/JNEUROSCI.3008-12.2013

Frech, G.C., VanDongen, A.M.J., Schuster, G., Brown, A.M. \& Joho, R.H. (1989) A novel potassium channel with delayed rectifier properties isolated from rat brain by expression cloning. Nature, 340, 642-645. doi:10.1038/340642a0

Gamper, N., Stockand, J.D. \& Shapiro, M.S. (2005) The use of Chinese hamster ovary (CHO) cells in the study of ion channels. Journal of Pharmacological and Toxicological Methods, 
51, 177-85. doi:10.1016/j.vascn.2004.08.008

Gayet-Primo, J., Yaeger, D.B., Khanjian, R.A. \& Puthussery, T. (2018) Heteromeric KV2/KV8.2 Channels Mediate Delayed Rectifier Potassium Currents in Primate Photoreceptors. The Journal of Neuroscience, 38, 3414-3427. doi:10.1523/JNEUROSCI.2440-17.2018

Gilchrist, J., Das, S., Petegem, F. Van \& Bosmans, F. (2013) Crystallographic insights into sodium-channel modulation by the $\beta 4$ subunit. Proceedings of the National Academy of Sciences of the United States of America, 110, E5016-24. doi:10.1073/pnas.1314557110 Gupta, K., Zamanian, M., Bae, C., Milescu, M., Krepkiy, D., Tilley, D.C., Sack, J.T., YarovYarovoy, V., Kim, J. Il \& Swartz, K.J. (2015) Tarantula toxins use common surfaces for interacting with Kv and ASIC ion channels. eLife, 4, e06774. doi:10.7554/eLife.06774

Herrington, J., Zhou, Y.P., Bugianesi, R.M., Dulski, P.M., Feng, Y., Warren, V.A., Smith, M.M., Kohler, M.G., Garsky, V.M., Sanchez, M., Wagner, M., Raphaelli, K., Banerjee, P., Ahaghotu, C., Wunderler, D., Priest, B.T., Mehl, J.T., Garcia, M.L., et al. (2006) Blockers of the Delayed-Rectifier Potassium Current in Pancreatic Beta-Cells Enhance GlucoseDependent Insulin Secretion. Diabetes, 55, 1034-1042. doi:10.2337/diabetes.55.04.06.db05-0788

Hönigsperger, C., Nigro, M.J. \& Storm, J.F. (2017) Physiological roles of Kv2 channels in entorhinal cortex layer II stellate cells revealed by Guangxitoxin-1E. The Journal of Physiology, 595, 739-757. doi:10.1113/JP273024

Irannejad, R., Tomshine, J.C., Tomshine, J.R., Chevalier, M., Mahoney, J.P., Steyaert, J., Rasmussen, S.G.F., Sunahara, R.K., El-Samad, H., Huang, B. \& Zastrow, M. von. (2013) Conformational biosensors reveal GPCR signalling from endosomes. Nature, 495, 534-8. doi:10.1038/nature 12000

Islas, L.D. \& Sigworth, F.J. (1999) Voltage sensitivity and gating charge in Shaker and Shab family potassium channels. The Journal of General Physiology, 114, 723-42. doi:10.1085/jgp.114.5.723

Jara-Oseguera, A., Ishida, I.G., Rangel-Yescas, G.E., Espinosa-Jalapa, N., Pérez-Guzmán, J.A., Elías-Viñas, D., Lagadec, R. Le, Rosenbaum, T. \& Islas, L.D. (2011) Uncoupling charge movement from channel opening in voltage-gated potassium channels by ruthenium complexes. The Journal of Biological Chemistry, 286, 16414-25. doi:10.1074/jbc.M110.198010

Johnson, B., Leek, A.N., Solé, L., Maverick, E.E., Levine, T.P. \& Tamkun, M.M. (2018) Kv2 potassium channels form endoplasmic reticulum/plasma membrane junctions via interaction with VAPA and VAPB. Proceedings of the National Academy of Sciences of the United States of America, 115, E7331-E7340. doi:10.1073/pnas.1805757115

Kaczmarek, L.K. (2006) Non-conducting functions of voltage-gated ion channels. Nature Reviews Neuroscience, 7, 761-771, Nature Publishing Group. doi:10.1038/nrn1988

Kihira, Y., Hermanstyne, T.O. \& Misonou, H. (2010) Formation of Heteromeric Kv2 Channels in Mammalian Brain Neurons. Journal of Biological Chemistry, 285, 15048-15055. doi:10.1074/jbc.M109.074260

Kimm, T., Khaliq, Z.M. \& Bean, B.P. (2015) Differential Regulation of Action Potential Shape and Burst-Frequency Firing by BK and Kv2 Channels in Substantia Nigra Dopaminergic Neurons. The Journal of Neuroscience, 35, 16404-17. doi:10.1523/JNEUROSCI.529114.2015

Kirmiz, M., Gillies, T.E., Dickson, E.J. \& Trimmer, J.S. (2019) Neuronal ER-plasma membrane junctions organized by Kv2-VAP pairing recruit Nir proteins and affect phosphoinositide 
homeostasis. The Journal of Biological Chemistry, 294, 17735-17757. doi:10.1074/jbc.RA119.007635

Kirmiz, Michael, Palacio, S., Thapa, P., King, A.N., Sack, J.T. \& Trimmer, J.S. (2018) Remodeling neuronal ER-PM junctions is a conserved nonconducting function of Kv2 plasma membrane ion channels. Molecular Biology of the Cell, 29, 2410-2432. doi:10.1091/mbc.E18-05-0337

Kirmiz, M., Vierra, N.C., Palacio, S. \& Trimmer, J.S. (2018) Identification of VAPA and VAPB as Kv2 Channel-Interacting Proteins Defining Endoplasmic Reticulum-Plasma Membrane Junctions in Mammalian Brain Neurons. The Journal of Neuroscience, 38, 7562-7584. doi:10.1523/JNEUROSCI.0893-18.2018

Kobrinsky, E., Stevens, L., Kazmi, Y., Wray, D. \& Soldatov, N.M. (2006) Molecular rearrangements of the Kv2.1 potassium channel termini associated with voltage gating. The Journal of Biological Chemistry, 281, 19233-40. doi:10.1074/jbc.M601231200

Lee, H.C., Wang, J.M. \& Swartz, K.J. (2003) Interaction between extracellular Hanatoxin and the resting conformation of the voltage-sensor paddle in Kv channels. Neuron, 40, 527-36. doi:10.1016/S0896-6273(03)00636-6

Lewis, G.N. (1925) A New Principle of Equilibrium. Proceedings of the National Academy of Sciences of the United States of America, 11, 179-83. doi:10.1073/pnas.11.3.179

Li, H., Guo, W., Xu, H., Hood, R., Benedict, A.T. \& Nerbonne, J.M. (2001) Functional expression of a GFP-tagged Kv1.5 alpha-subunit in mouse ventricle. American Journal of Physiology. Heart and Circulatory Physiology, 281, H1955-67. doi:10.1152/ajpheart.2001.281.5.H1955

Lin, M.Z. \& Schnitzer, M.J. (2016) Genetically encoded indicators of neuronal activity. Nature Neuroscience, 19, 1142-1153. doi:10.1038/nn.4359

Liu, P.W. \& Bean, B.P. (2014) Kv2 channel regulation of action potential repolarization and firing patterns in superior cervical ganglion neurons and hippocampal CA1 pyramidal neurons. The Journal of Neuroscience, 34, 4991-5002. doi:10.1523/JNEUROSCI.192513.2014

Long, S.B., Campbell, E.B. \& Mackinnon, R. (2005) Voltage Sensor of Kv1.2: Structural Basis of Electromechanical Coupling. Science, 309, 903-908. doi:10.1126/science.1116270

Long, S.B., Tao, X., Campbell, E.B. \& MacKinnon, R. (2007) Atomic structure of a voltagedependent $\mathrm{K}+$ channel in a lipid membrane-like environment. Nature, 450, 376-82. doi:10.1038/nature06265

Maffie, J.K., Dvoretskova, E., Bougis, P.E., Martin-Eauclaire, M.-F. \& Rudy, B. (2013) Dipeptidyl-peptidase-like-proteins confer high sensitivity to the scorpion toxin AmmTX3 to Kv4-mediated A-type K+ channels. The Journal of Physiology, 591, 2419-27. doi:10.1113/jphysiol.2012.248831

Maletic-Savatic, M., Lenn, N.J. \& Trimmer, J.S. (1995) Differential spatiotemporal expression of $\mathrm{K}+$ channel polypeptides in rat hippocampal neurons developing in situ and in vitro. The Journal of Neuroscience, 15, 3840-51.

Malin, S.A., Nerbonne, J.M. \& Tamkun, M.M. (2013) Delayed Rectifier K+ Currents, IK, Are Encoded by Kv2 alpha -Subunits and Regulate Tonic Firing in Mammalian Sympathetic Neurons. Journal of Neuroscience, 22, 10094-10105. doi:10.1523/jneurosci.3008-12.2013

McCord, M.C. \& Aizenman, E. (2013) Convergent Ca2+ and Zn2+ signaling regulates apoptotic Kv2.1 K+ currents. Proceedings of the National Academy of Sciences of the United States of America, 110, 13988-93. doi:10.1073/pnas.1306238110 
McCormack, K., Santos, S., Chapman, M.L., Krafte, D.S., Marron, B.E., West, C.W., Krambis, M.J., Antonio, B.M., Zellmer, S.G., Printzenhoff, D., Padilla, K.M., Lin, Z., Wagoner, P.K., Swain, N.A., Stupple, P.A., Groot, M. de, Butt, R.P. \& Castle, N.A. (2013) Voltage sensor interaction site for selective small molecule inhibitors of voltage-gated sodium channels. Proceedings of the National Academy of Sciences of the United States of America, 110, E2724-E2732. doi:10.1073/pnas.1220844110

McDonough, S.I., Mintz, I.M. \& Bean, B.P. (1997) Alteration of P-type calcium channel gating by the spider toxin omega-Aga-IVA. Biophysical Journal, 72, 2117-28. doi:10.1016/S0006-3495(97)78854-4

Milescu, M., Bosmans, F., Lee, S., Alabi, A.A., Kim, J. Il \& Swartz, K.J. (2009) Interactions between lipids and voltage sensor paddles detected with tarantula toxins. Nature structural \& molecular biology, 16, 1080-5. doi:10.1038/nsmb.1679

Misonou, H., Mohapatra, D.P., Park, E.W., Leung, V., Zhen, D., Misonou, K., Anderson, A.E. \& Trimmer, J.S. (2004) Regulation of ion channel localization and phosphorylation by neuronal activity. Nature Neuroscience, 7, 711-8. doi:10.1038/nn1260

Misonou, H., Mohapatra, D.P., Menegola, M. \& Trimmer, J.S. (2005) Calcium- and metabolic state-dependent modulation of the voltage-dependent Kv2.1 channel regulates neuronal excitability in response to ischemia. The Journal of Neuroscience, 25, 11184-93. doi:10.1523/JNEUROSCI.3370-05.2005

O’Connell, K.M.S., Loftus, R. \& Tamkun, M.M. (2010) Localization-dependent activity of the Kv2.1 delayed-rectifier K+ channel. Proceedings of the National Academy of Sciences of the United States of America, 107, 12351-6.doi:10.1073/pnas.1003028107

Opitz-Araya, X. \& Barria, A. (2011) Organotypic hippocampal slice cultures. Journal of Visualized Experiments, MyJoVE Corporation. doi:10.3791/2462

Pal, S., Hartnett, K.A., Nerbonne, J.M., Levitan, E.S. \& Aizenman, E. (2003) Mediation of neuronal apoptosis by Kv2.1-encoded potassium channels. The Journal of Neuroscience, 23, 4798-802. doi: 10.1523/JNEUROSCI.23-12-04798.2003

Park, K.S., Mohapatra, D.P., Misonou, H. \& Trimmer, J.S. (2006) Graded regulation of the Kv2.1 potassium channel by variable phosphorylation. Science, 313, 976-9. doi:10.1126/science.1124254

Peltola, M.A., Kuja-Panula, J., Lauri, S.E., Taira, T. \& Rauvala, H. (2011) AMIGO is an auxiliary subunit of the Kv2.1 potassium channel. EMBO Reports, 12, 1293-1299. doi:10.1038/embor.2011.204

Peretz, A., Pell, L., Gofman, Y., Haitin, Y., Shamgar, L., Patrich, E., Kornilov, P., GourgyHacohen, O., Ben-Tal, N. \& Attali, B. (2010) Targeting the voltage sensor of Kv7.2 voltage-gated $\mathrm{K}+$ channels with a new gating-modifier. Proceedings of the National Academy of Sciences of the United States of America, 107, 15637-42. doi:10.1073/pnas.0911294107

Pologruto, T.A., Sabatini, B.L. \& Svoboda, K. (2003) ScanImage: flexible software for operating laser scanning microscopes. Biomedical Engineering Online, 2, 13. doi:10.1186/1475925X-2-13

Sack, J.T., Aldrich, R.W. \& Gilly, W.F. (2004) A gastropod toxin selectively slows early transitions in the Shaker K channel's activation pathway. The Journal of General Physiology, 123, 685-96. doi:10.1085/jgp.200409047

Sack, J.T., Stephanopoulos, N., Austin, D.C., Francis, M.B. \& Trimmer, J.S. (2013) Antibodyguided photoablation of voltage-gated potassium currents. The Journal of General 
Physiology, 142, 315-24. doi:10.1085/jgp.201311023

Schmalhofer, W.A., Calhoun, J., Burrows, R., Bailey, T., Kohler, M.G., Weinglass, A.B., Kaczorowski, G.J., Garcia, M.L., Koltzenburg, M. \& Priest, B.T. (2008) ProTx-II, a selective inhibitor of NaV1.7 sodium channels, blocks action potential propagation in nociceptors. Molecular Pharmacology, 74, 1476-84. doi:10.1124/mol.108.047670

Schneider, C.A., Rasband, W.S. \& Eliceiri, K.W. (2012) NIH Image to ImageJ: 25 years of image analysis. Nature Methods, 9, 671-5. doi:10.1038/nmeth.2089

Schneider, M.F. \& Chandler, W.K. (1973) Voltage dependent charge movement of skeletal muscle: a possible step in excitation-contraction coupling. Nature, 242, 244-6. doi: $10.1038 / 242244 \mathrm{a} 0$

Scholle, A., Dugarmaa, S., Zimmer, T., Leonhardt, M., Koopmann, R., Engeland, B., Pongs, O. \& Benndorf, K. (2004) Rate-limiting reactions determining different activation kinetics of Kv1.2 and Kv2.1 channels. The Journal of Membrane Biology, 198, 103-12. doi:10.1007/s00232-004-0664-0

Seoh, S.A., Sigg, D., Papazian, D.M. \& Bezanilla, F. (1996) Voltage-sensing residues in the S2 and S4 segments of the Shaker K+ channel. Neuron, 16, 1159-67. doi:10.1016/S08966273(00)80142-7

Shi, G., Kleinklaus, A.K., Marrion, N. V \& Trimmer, J.S. (1994) Properties of Kv2.1 K+ channels expressed in transfected mammalian cells. The Journal of Biological Chemistry, 269, 23204-11.

Shi, G., Nakahira, K., Hammond, S., Rhodes, K.J., Schechter, L.E. \& Trimmer, J.S. (1996) Beta subunits promote $\mathrm{K}+$ channel surface expression through effects early in biosynthesis. Neuron, 16, 843-52. doi:10.1016/S0896-6273(00)80104-X

Shibata, R., Misonou, H., Campomanes, C.R., Anderson, A.E., Schrader, L.A., Doliveira, L.C., Carroll, K.I., Sweatt, J.D., Rhodes, K.J. \& Trimmer, J.S. (2003) A fundamental role for KChIPs in determining the molecular properties and trafficking of Kv4.2 potassium channels. The Journal of Biological Chemistry, 278, 36445-54. doi:10.1074/jbc.M306142200

Shimony, E., Sun, T., Kolmakova-Partensky, L. \& Miller, C. (1994) Engineering a uniquely reactive thiol into a cysteine-rich peptide. Protein Engineering, 7, 503-7. doi:10.1093/protein/7.4.503

Singer-Lahat, D., Sheinin, A., Chikvashvili, D., Tsuk, S., Greitzer, D., Friedrich, R., Feinshreiber, L., Ashery, U., Benveniste, M., Levitan, E.S. \& Lotan, I. (2007) K+ channel facilitation of exocytosis by dynamic interaction with syntaxin. The Journal of Neuroscience, 27, 1651-8. doi:10.1523/JNEUROSCI.4006-06.2007

Speca, D.J., Ogata, G., Mandikian, D., Bishop, H.I., Wiler, S.W., Eum, K., Wenzel, H.J., Doisy, E.T., Matt, L., Campi, K.L., Golub, M.S., Nerbonne, J.M., Hell, J.W., Trainor, B.C., Sack, J.T., Schwartzkroin, P.A. \& Trimmer, J.S. (2014) Deletion of the Kv2.1 delayed rectifier potassium channel leads to neuronal and behavioral hyperexcitability. Genes, Brain and Behavior, 13, 394-408. doi:10.1111/gbb.12120

Stoppini, L., Buchs, P.A. \& Muller, D. (1991) A simple method for organotypic cultures of nervous tissue. Journal of Neuroscience Methods, 37, 173-82. doi:10.1016/01650270(91)90128-M

Swartz, K.J. (2007) Tarantula toxins interacting with voltage sensors in potassium channels. Toxicon, 49, 213-30. doi:10.1016/j.toxicon.2006.09.024

Tao, X., Lee, A., Limapichat, W., Dougherty, D.A. \& MacKinnon, R. (2010) A Gating Charge 
Transfer Center in Voltage Sensors. Science, 328, 67-73. doi:10.1126/science.1185954

Tilley, D.C., Angueyra, J.M., Eum, K.S., Kim, H., Chao, L.H., Peng, A.W. \& Sack, J.T. (2019) The tarantula toxin GxTx detains $\mathrm{K}+$ channel gating charges in their resting conformation. The Journal of General Physiology, 151, 292-315. doi:10.1085/jgp.201812213

Tilley, D.C., Eum, K.S., Fletcher-Taylor, S., Austin, D.C., Dupre, C., Patron, L.A., Garcia, R.L., Lam, K., Yarov-Yarovoy, V., Cohen, B.E. \& Sack, J.T. (2014) Chemoselective tarantula toxins report voltage activation of wild-type ion channels in live cells. Proceedings of the National Academy of Sciences of the United States of America, 111, E4789-96. doi:10.1073/pnas.1406876111

Trapani, J.G. \& Korn, S.J. (2003) Control of ion channel expression for patch clamp recordings using an inducible expression system in mammalian cell lines. BMC Neuroscience, 4, 15. doi:10.1186/1471-2202-4-15

Trimmer, J.S. (1991) Immunological identification and characterization of a delayed rectifier K+ channel polypeptide in rat brain. Proceedings of the National Academy of Sciences of the United States of America, 88, 10764-8. doi:10.1073/pnas.88.23.10764

Tsvetanova, N.G., Irannejad, R. \& Zastrow, M. von. (2015) G Protein-coupled Receptor (GPCR) Signaling via Heterotrimeric G Proteins from Endosomes. Journal of Biological Chemistry, 290, 6689-6696. doi:10.1074/jbc.R114.617951

Turner, M., Anderson, D., Nieves, M., Bartels, P., Coleman, A., Henderson, P., Man, K.N.M., Yarov-Yarovoy, V., Bers, D., Navedo, M., Horne, M., Ames, J.B. \& Hell, J. (2019) $\alpha-$ Actinin-1 promotes activity of the L-type Ca2+ Channel Cav1.2. EMBO (In Press).

Vacher, H., Mohapatra, D.P. \& Trimmer, J.S. (2008) Localization and targeting of voltagedependent ion channels in mammalian central neurons. Physiological Reviews, 88, 140747. doi:10.1152/physrev.00002.2008

Vierra, N.C., Kirmiz, M., List, D. van der, Santana, L.F. \& Trimmer, J.S. (2019) Kv2.1 mediates spatial and functional coupling of L-type calcium channels and ryanodine receptors in mammalian neurons. eLife, 8. doi:10.7554/eLife.49953

Woods, G. \& Zito, K. (2008) Preparation of gene gun bullets and biolistic transfection of neurons in slice culture. Journal of Visualized Experiments, pii:675. doi:10.3791/675

Xia, X.M., Ding, J.P. \& Lingle, C.J. (1999) Molecular basis for the inactivation of Ca2+- and voltage-dependent BK channels in adrenal chromaffin cells and rat insulinoma tumor cells. The Journal of Neuroscience, 19, 5255-64. doi:10.1523/jneurosci.19-13-05255.1999

Xu, H., Barry, D.M., Li, H., Brunet, S., Guo, W. \& Nerbonne, J.M. (1999) Attenuation of the Slow Component of Delayed Rectification, Action Potential Prolongation, and Triggered Activity in Mice Expressing a Dominant-Negative Kv2 $\alpha$ Subunit. Circulation Research, 85, 623-633. doi:10.1161/01.RES.85.7.623

Xu, Hui, Li, T., Rohou, A., Arthur, C.P., Tzakoniati, F., Wong, E., Estevez, A., Kugel, C., Franke, Y., Chen, J., Ciferri, C., Hackos, D.H., Koth, C.M. \& Payandeh, J. (2019) Structural Basis of Nav1.7 Inhibition by a Gating-Modifier Spider Toxin. Cell, 176, 1238-1239. doi:10.1016/j.cell.2019.01.047

Yang, F. \& Zheng, J. (2014) High temperature sensitivity is intrinsic to voltage-gated potassium channels. eLife, 3, e03255. doi:10.7554/eLife.03255

Yang, W. \& Yuste, R. (2017) In vivo imaging of neural activity. Nature Methods, 14, 349-359. doi:10.1038/nmeth.4230

Zagotta, W.N., Hoshi, T., Dittman, J. \& Aldrich, R.W. (1994) Shaker potassium channel gating. II: Transitions in the activation pathway. The Journal of General Physiology, 103, 279-319. 
doi:10.1085/jgp.103.2.279

Zhang, A.H., Sharma, G., Undheim, E.A.B., Jia, X. \& Mobli, M. (2018) A complicated complex: Ion channels, voltage sensing, cell membranes and peptide inhibitors. Neuroscience Letters, 679, 35-47. doi:10.1016/j.neulet.2018.04.030

Zhang, G., Zheng, S., Liu, H. \& Chen, P.R. (2015) Illuminating biological processes through site-specific protein labeling. Chemical Society Reviews, 44, 3405-3417. doi:10.1039/C4CS00393D

Zito, K., Knott, G., Shepherd, G.M.G., Shenolikar, S. \& Svoboda, K. (2004) Induction of Spine Growth and Synapse Formation by Regulation of the Spine Actin Cytoskeleton. Neuron, 44, 321-334. doi:10.1016/j.neuron.2004.09.022 


\section{Figure Legends}

\section{Figure 1: GxTX-594 colocalizes with Kv2-GFP.}

A. Fluorescence from CHO cells transfected with Kv2.1-GFP (Top) or Kv2.2-GFP (Bottom) and labeled with GxTX-594. Optical sections were near the glass-adhered cell surface. Cells were incubated with 100 nM GxTX-594 for 5 minutes and rinsed before imaging. Fluorescence shown corresponds to emission of GFP (Left), Alexa Fluor 594 (Middle), or an overlay of GFP and Alexa Fluor 594 (Right). Scale bars are $20 \mu \mathrm{m}$.

B. Pearson correlation coefficient for GxTX-594 colocalization with Kv2.1-GFP or Kv2.2GFP.

C. Ratio of magenta to green intensity between GxTX-594 and Kv2-GFP. Circles indicate measurements from individual cells. In panels B and C, pixel intensities were background subtracted before analyses by subtracting the average fluorescence of a background ROI that did not contain cells, from the ROI containing the cell. All data from the same application of GxTX-594. Bars are arithmetic mean. 
Figure 1 Supplement 1: Synthesis of GxTX-594.

A. Molecular model of GxTX-594. Scale bar is 10 angstroms.

B. HPLC chromatogram of Ser13Cys GxTX. Gradient described in Methods Ser13Cys GxTX eluted at 12.6 minutes, peak 1, which corresponds to 33\% acetonitrile. MALDITOF MS profile of peak 1 (Inset). Rel. Int. is Relative Intensity.

C. HPLC chromatogram of GxTX-594 conjugation reaction between Alexa Fluor 594maleimide and Ser13Cys GxTX. Peak 1 is Ser13Cys GxTX (Retention time: 12.8 minutes, $33 \%$ acetonitrile), peak 2 is a minor product from conjugation, and peak 3 is GxTX-594, the major product from conjugation (Retention time: 16.4 minutes, 35\% acetonitrile). The fractions corresponding to peak 3 were combined.

D. HPLC chromatogram of the combined peak 3 fractions from panel C, a GxTX-594 preparation used in this study. $2 \mu \mathrm{L}$ of $13.1 \mu \mathrm{M}$ GxTX-594 diluted in $200 \mu \mathrm{L}$ of $0.1 \%$ TFA was injected. MALDI-TOF MS profile of the combined peak 3 fractions (Inset). 
Figure 2: GxTX594 binds Kv2.1 in the presence of its auxiliary subunit AMIGO-1.

A. Fluorescence from Kv2.1-CHO cells, some of which have been transfected with AMIGO-1-YFP. Imaging plane was near the glass-adhered cell surface. Cells were incubated in indicated concentrations of GxTX-594 for 15 minutes then washed out before imaging. Fluorescence shown corresponds to YFP (Green) and Alexa Fluor 594 (Magenta). Scale bar is $20 \mu \mathrm{m}$. Green line surrounds a representative AMIGO-1 positive ROI. Blue line surrounds an AMIGO-1 negative ROI.

B. Pearson correlation coefficient between AMIGO-1-YFP and GxTX-594 within AMIGO positive ROIs. Coefficients from $1000 \mathrm{nM}$ dose of GxTX-594. $\mathrm{n}=8$ ROIs total over 3 independent experiments. Bar is arithmetic mean.

C. Time-lapse GxTX-594 fluorescence intensity from the dose-response experiment shown in $\mathrm{A}$. The green trace represents the AMIGO-1-YFP positive ROI, the blue trace represents the AMIGO-1-YFP negative ROI. Fluorescence was not backgroundsubtracted. $F_{\max }$ is intensity while cells were incubated in 1000 nM GxTX-594.

D. Changes in fluorescence were analyzed at each concentration from multiple dose response experiments. Hollow markers correspond to 3 independent experiments. Green represents AMIGO-1-YFP positive ROIs, blue represents AMIGO-1-YFP negative ROIs. Lines are fits of a Langmuir isotherm (Hill equation with slope held at 1) to obtain a dissociation constant $\left(K_{d}\right)$ for GxTX-594; AMIGO-1-YFP positive $K_{d}=26.7 \mathrm{nM} \pm 14.3$; AMIGO-1-YFP negative $K_{d}=26.9 \mathrm{nM} \pm 8.3$. 
Figure 3: GxTX-594 labeling responds to transmembrane voltage.

A. Fluorescence intensities from an optical section of a voltage-clamped Kv2.1- CHO cell in 9 nM GxTX-594. Pseudocolored images indicate maximal intensities in white. Rows indicate voltage step taken from a holding potential of $-80 \mathrm{mV}$. Columns indicate time after voltage step. Scale bar is $10 \mu \mathrm{m}$.

B. GxTX-594 fluorescence during steps to indicated voltages. Smooth lines are fits of monoexponential (Eq. 1): $-40 \mathrm{mV} k_{\Delta F}=2.2 \times 10^{-2} \pm 2.2 \times 10^{-3} \mathrm{~s}^{-1}: 0 \mathrm{mV} k_{\Delta F}=1.3 \times 10^{-1} \pm$ $2.3 \times 10^{-3} \mathrm{~s}^{-1}, 40 \mathrm{mV} k_{\Delta F}=2.6 \times 10^{-1} \pm 6.2 \times 10^{-3} \mathrm{~s}^{-1}$ and $80 \mathrm{mV} k_{\Delta F}=5.3 \times 10^{-1} \pm 1.1 \mathrm{x}$ $10^{-2} \mathrm{~s}^{-1}$. ROIs were hand-drawn around the apparent cell surface membrane based on GxTX-594 fluorescence. Background for subtraction was the average intensity of a region that did not contain cells over the time course of the voltage protocol. Each trace was normalized to initial fluorescence intensity before the application of the voltage stimulus.

C. Fluorescence intensity remaining at the end of $50 \mathrm{~s}$ steps to $+80 \mathrm{mV}$. Each circle represents one cell. Background subtraction and normalization as in panel B.

D. Voltage-dependence of fluorescence intensity at the end of $50 \mathrm{~s}$ steps. Data normalized to $100 \%$ for $-80 \mathrm{mV}$ and $0 \%$ for $+80 \mathrm{mV}$. Circle coloring indicates data from the same cell. Gray circles represent data shown in B. Black line is fit of a first-order Boltzmann equation as in Tilley et al., 2019: $V_{1 / 2}=-27.4 \pm 2.5 \mathrm{mV}, z=-1.38 \pm 0.13 e_{0}$. Blue line is prediction from Scheme I at $9 \mathrm{nM}$ GxTX. Bars are arithmetic mean \pm standard error.

E. Voltage dependence of fluorescence intensity kinetics at end of $50 \mathrm{~s}$ steps. Circle coloring is the same as panel D. Black line is a first-order Boltzmann equation fit to the logarithm of $\mathrm{k} \Delta \mathrm{F}: V_{l / 2}=2.3 \pm 7.9 \mathrm{mV}, z=-1.14 \pm 0.38 e_{0}$. Blue line is prediction from Scheme I at 9 $\mathrm{nM}$ GxTX. Bars are geometric mean \pm standard error. 
Figure 3 Supplement 1: Spatial dependence of GxTX-594 labeling kinetics at the glass-adhered surface.

We conducted experiments to determine the region of voltage-clamped cells from which to quantify dynamic fluorescence. The confocal imaging plane containing the most GxTX-594 fluorescence was the glass-adhered basal surface. We noticed that GxTX-594 fluorescence in the center of the basal surface appeared to respond more slowly to voltage changes than the periphery. To quantify this observation, concentric ROIs were drawn in the center of the basal surface of the cell and their average fluorescence intensities were compared to each other and an ROI at the cell periphery. In response to voltage change, the kinetics of fluorescence change were slower at the center of the basal surface and faster towards the outer periphery. We quantified rates of fluorescence change $\left(k_{\Delta F}\right)$ by fitting a monoexponential function (Eq 1). $k_{\Delta F}$ progressively slowed as the ROI contracted from the perimeter of the cell. This difference in kinetics suggests that the concentration of freely diffusing GxTX-594 in the restricted space between the cell membrane and the glass surface is transiently non-uniform after voltage change. The location dependence of $k_{\Delta F}$ was more pronounced during GxTX-594 labeling at -80 mV than unlabeling at $+40 \mathrm{mV}$. We suspect that the more extreme location dependence at $-80 \mathrm{mV}$ is due to a high density of Kv2.1 binding sites in the restricted extracellular space between the cell membrane and glass coverslip, such that GxTX-594 is depleted from solution by binding Kv2.1 before reaching the center of the cell. After unbinding at $+40 \mathrm{mV}$, each GxTX-594 molecule is expected to be less likely to rebind to Kv2.1 proteins as it diffuses out from under the cell, because Kv2.1 voltage sensors are in an activated, low affinity conformation (Tilley et al. 2014, 2019). This expected difference in GxTX-594 buffering by Kv2.1 could explain the difference in location dependence of $k_{\Delta F}$ during labeling at $-80 \mathrm{mV}$ and unlabeling at $+40 \mathrm{mV}$. To avoid complications resulting from the spatial variability of kinetics at the basal surface, further voltage-dependent labeling experiments were conducted while imaging at a plane above the coverslip, where the cell surface has unrestricted access to the extracellular solution.

A. Time lapse airy disk images of the glass-adhered surface of a voltage-clamped Kv2.1CHO cell in 9 nM GxTX-594. Time index is in the upper left of each panel and membrane potential is indicated in the upper right. Scale bar in lower right of last panel is $10 \mu \mathrm{m}$ 
B. Airy disk image of the glass adhered surface of a voltage-clamped Kv2.1-CHO cell in 9 nM GxTX-594. Grey lines indicate boundaries of ROIs. ROI 1, 2, and 3 are concentric circles each with a respective diameter of $1.8,4.9$, and $9.1 \mu \mathrm{m}$. ROI 4 was hand-drawn to contain the apparent cell surface. In all cells analyzed, ROI 1-3 were concentric circles of the same sizes, while ROI 4 varied based on cell shape. Scale bar is $10 \mu \mathrm{m}$.

C. Representative traces of GxTX-594 fluorescence intensity response to voltage changes. Red lines are monoexponential fits (Eq. 1): $40 \mathrm{mV}$ step ROI $1 k_{\Delta F}=4.3 \times 10^{-2} \pm 2.6 \times 10^{-}$ ${ }^{3} \mathrm{~s}^{-1}$, ROI $2 k_{\Delta F}=4.4 \times 10^{-2} \pm 1.6 \times 10^{-3} \mathrm{~s}^{-1}$, ROI $3 k_{\Delta F}=5.7 \times 10^{-2} \pm 1.5 \times 10^{-3} \mathrm{~s}^{-1}$, ROI 4 $k_{\Delta F}=9.7 \times 10^{-2} \pm 3.3 \times 10^{-3} \mathrm{~s}^{-1} .-80 \mathrm{mV}$ step ROI $1 k_{\Delta F}=4.3 \times 10^{-4} \pm 1.1 \times 10^{-5} \mathrm{~s}^{-1}$, ROI 2 $k_{\Delta F}=7.9 \times 10^{-4} \pm 5.3 \times 10^{-6} \mathrm{~s}^{-1}$, ROI $3 k_{\Delta F}=2.8 \times 10^{-3} \pm 7.4 \times 10^{-6} \mathrm{~s}^{-1}$, and ROI $4 k_{\Delta F}=$ $5.5 \times 10^{-3} \pm 1.3 \times 10^{-4} \mathrm{~s}^{-1}$. Background for subtraction was the average intensity of a region that did not contain cells over the time course of the voltage protocol. Each trace was normalized to initial fluorescence intensity before the application of the voltage stimulus.

D. Circles indicate $k_{\Delta F}$ at $40 \mathrm{mV}$ from individual cells. Circle coloring indicates data from the same cell.

E. Circles indicate $k_{\Delta F}$ at $-80 \mathrm{mV}$ from individual cells. Circle coloring indicates data from the same cell. 
Figure 3 Supplement 2: Temperature dependence of GxTX-594 on Kv2.1 CHO cells.

To assess the temperature dependence of GxTX-594 labeling, the cell bath solution was held at either $27^{\circ} \mathrm{C}$ or $37^{\circ} \mathrm{C}$ and stepped to $0 \mathrm{mV}$ for a measurement of $k_{\Delta F}$. The fold change in $k_{\Delta F}$ over this $10{ }^{\circ} \mathrm{C}$ difference, or $\mathrm{Q}_{10}$, was 3.8-fold. This $\mathrm{Q}_{10}$ predicts a 1.3-fold increase in $k_{\Delta F}$ between 27 and $29^{\circ} \mathrm{C}$, the temperature range of expreiments reported in Fig 3 E. This 1.3-fold increase was less than cell-to-cell variability observed.

A. Representative traces of GxTX-594 fluorescence intensity response to voltage changes at $27^{\circ} \mathrm{C}$ (black) and $37^{\circ} \mathrm{C}$ (gray). Smooth lines are fits of a monoexponential function (Eq. 1): $27^{\circ} \mathrm{C} k_{\Delta F}=2.8 \times 10^{-2} \pm 3.9 \times 10^{-3} \mathrm{~s}^{-1} ; 37^{\circ} \mathrm{C} k_{\Delta F}=7.5 \times 10^{-2} \pm 5.4 \times 10^{-3} \mathrm{~s}^{-1}$. Background was determined by taking the average fluorescence of a region that did not contain cells over the time course of the voltage protocol. This average was subtracted from each experimental group. Traces were normalized to initial fluorescence intensity before the application of the voltage stimulus.

B. $k_{\Delta F}$ at $27^{\circ} \mathrm{C}$ and $37^{\circ} \mathrm{C}$. The rate of fluorescence change was significantly faster at higher temperatures (Mann-Whitney $\mathrm{p}=0.0005)$. From geometric means (Bars), a $\mathrm{Q}_{10}$ of 3.8 was calculated between $27^{\circ} \mathrm{C}$ and $37^{\circ} \mathrm{C}$. Each circle represents one cell, $\mathrm{n}=7$ both groups. 


\section{Figure 4: Frequency dependence of GxTX-594 response}

A. Fluorescence intensity on Kv2.1-expressing CHO cells incubated in 9 nM GxTX-594. GxTX-594 fluorescence before (Left), after $50 \mathrm{~s}$ of $200 \mathrm{~Hz}$ stimulus (Middle), and $100 \mathrm{~s}$ after the cell is returned to resting potential of $-80 \mathrm{mV}$ (Right). Note that in each panel the unpatched cell (Left cell in each panel) does not show a change in fluorescence. Scale bar is $10 \mu \mathrm{m}$. Patched cell is indicated by a white arrow.

B. Representative trace of GxTX-594 unlabeling at $200 \mathrm{~Hz}$. The trace was fit using a monoexponential (Eq. 1). Fit is overlaid and is in red. The $k_{\Delta F}$ at $200 \mathrm{~Hz}$ was obtained from this fit. For $200 \mathrm{~Hz} k_{\Delta F}=2.23 \times 10^{-1} \pm 9.9 \times 10^{-3} \mathrm{~s}^{-1}$. ROIs were hand drawn capturing the cell membrane based on GxTX-594 fluorescence such that only the cell membrane was selected without selecting the dark intracellular region. Background was determined by taking the average fluorescence of a region that did not contain cells over the time course of the protocol. This average was subtracted from each experimental group. $F_{\text {init }}$ is the initial fluorescence intensity before the application of the frequency stimulus.

C. Decrease in fluorescence with increasing stimulus frequency. Circles indicate $F / F_{\text {init }}$ from individual cells when stepped to $+40 \mathrm{mV}$ at indicated frequencies from a holding potential of $-80 \mathrm{mV}$. Data normalized to $100 \%$ for $-80 \mathrm{mV}$ before frequency pulse. Circle coloring indicates data from the same cell. Black line is fit of a first-order Boltzmann equation as in Tilley et al., 2019: $V_{1 / 2}=-0.35 \pm 0.03 \mathrm{mV}, z=51.23 \pm 5.19 e_{0}$. Blue line represents decreases in fluorescence at increasing voltages derived from the model shown in Scheme I at a concentration of $9 \mathrm{nM}$. Bars are arithmetic mean \pm standard error.

D. Increases in $k_{\Delta F}$ with increasing stimulus frequency. Rates were obtained from fitting decreases in fluorescence with a monoexponential (Eq. 1) as shown in B. Blue line represents the rates of fluorescence change at increasing frequencies derived from the model shown in Scheme I at a concentration of $9 \mathrm{nM}$. Bars are geometric mean \pm standard error. 


\section{Figure 5: Relationship of GxTX-594 labeling to probability of Kv2 voltage sensor activation.}

A. Scheme I model predictions of concentration- and voltage-dependence of cell surface fluorescence intensity. Bottom axis represents membrane voltage while the top axis represents the ratio of activated to resting voltage sensors for unlabeled Kv2.1. Dashed black line represents the probability that voltage sensors of unlabeled Kv2.1 are in their resting conformation.

B. Scheme I model predictions of concentration- and voltage-dependence of $k_{\Delta F}$. Colors correspond to panel A. 


\section{Figure 6: GxTX-594 is selective for Kv2 proteins.}

A. Fluorescence from live $\mathrm{CHO}$ cells transfected with Kv2.1-GFP, Kv2.2-GFP, Kv4.2-GFP $+\mathrm{KChIP} 2$, Kv1.5-GFP + Kv $\beta 2$, or BK-GFP (Indicated by row) and labeled with GxTX594. Airy disk imaging was from a plane above the glass-adhered surface. Cells were incubated with $100 \mathrm{nM}$ GxTX-594 and $5 \mu \mathrm{g} / \mathrm{mL}$ WGA-405 then rinsed before imaging. Fluorescence shown corresponds to emission of GFP (Column 1), Alexa Fluor 594 (Column 2), WGA-405 (Column 3), or an overlay of GFP, Alexa Fluor 594, and WGA405 (Column 4). Scale bars are $20 \mu \mathrm{m}$.

B. GxTX-594:GFP fluorescence intensity ratios for different $\mathrm{K}^{+}$channel-GFP types. $F_{\text {init }}$ is the average GxTX-594:Kv2.1-GFP ratio. Circles indicate measurements from individual cells. Only cells with obvious GFP expression were analyzed. For analysis ROIs were drawn around the cell membrane indicated by WGA-405 fluorescence. Pixel intensities were background-subtracted before analyses by subtracting the average fluorescence of a background ROI that did not contain cells from the ROI containing the cell; this occasionally resulted in ROIs with negative intensity. Kv2.1 n = 16, Kv2.2 n=10, Kv4.2 $\mathrm{n}=13, \mathrm{Kv} 1.5 \mathrm{n}=13, \mathrm{BK} \mathrm{n}=10 ; \mathrm{n}$ indicates the number of individual cells analyzed during a single application of GxTX-594. Bars are arithmetic mean. Significant differences were observed between GxTX:GFP ratio for Kv2.1 or Kv2.2 and Kv1.5, Kv4.2, or BK by Mann-Whitney $(\mathrm{p}<0.0001)$.

C. Pearson correlation coefficients between GxTX-594 and GFP. Same cells as panel B. Significant differences were observed between correlation coefficients for Kv2.1 or Kv2.2 and Kv1.5, Kv4.2, or BK by Mann-Whitney ( $\mathrm{p}<0.0001)$. 
Figure 6 Supplement 1: GFP-tagged $\boldsymbol{K}^{+}$channels exhibit expected outward currents.

A. Exemplar whole-cell voltage clamp recordings of CHO cells expressing Kv2.1-GFP, Kv2.2-GFP, Kv4.2-GFP, Kv1.5-GFP, or BK-GFP. Recordings shown are representative responses to $100 \mathrm{~ms}$ steps from $-100 \mathrm{mV}$ to $-40,0$ and $+40 \mathrm{mV}$.

B. Fluorescence from live $\mathrm{CHO}$ cells transfected with Kv2.1-GFP, Kv2.2-GFP, Kv4.2-GFP Kv1.5-GFP, or BK-GFP (Indicated by row) and labeled with GxTX-594. Confocal imaging plane was above the glass-adhered surface. Cells were incubated with $100 \mathrm{nM}$ GxTX-594 and $5 \mu \mathrm{g} / \mathrm{mL}$ WGA-405 and rinsed before imaging. Fluorescence shown corresponds to emission of GFP (Column 1), Alexa Fluor 594 (Column 2), WGA-405 (Column 3), or an overlay of GFP, Alexa Fluor 594, and WGA-405 (Column 4). Scale bars are $20 \mu \mathrm{m}$.

C. Background-subtracted GxTX-594:GFP ratio for different GFP and $\mathrm{K}^{+}$channel subtypes normalized to the average GxTX-594:Kv2.1-GFP ratio. Analysis same as in Figure 6 B. Kv2.1 n = 11, Kv2.2 n = 9, Kv4.2 n=13, Kv1.5 = 13, and BK n =12. Cells were compiled from two independent GxTX-594 applications, each circle corresponds to a cell. Significant differences were observed between GxTX:GFP ratio for Kv2.1 or Kv2.2 and Kv1.5, Kv4.2, or BK by Mann-Whitney ( $<<0.0001)$.

D. Pearson correlation coefficients between GxTX-594 and GFP. Unless otherwise noted analysis was same as in Figure $6 \mathrm{C}$. Same cells as panel C. 
Figure 7: GxTX-594 labels CA1 hippocampal pyramidal neurons transfected with Kv2.1-

\section{GFP.}

A. Two-photon excitation images of fluorescence from the soma and proximal dendrites of a rat CA1 hippocampal pyramidal neuron in a brain slice six days after transfection with Kv2.1-GFP (Left), labeled with 100 nM GxTX-594 (Middle) and overlay (Right). Image represents a z-projection of 20 optical sections. Scale bar $10 \mu \mathrm{m}$.

B. A single optical section of the two-photon excitation image shown in A. GxTX-594 labels both Kv2.1-GFP puncta from a transfected cell and apparent endogenous Kv2 proteins from an untransfected cell in the same cultured slice (Right, arrow).

C. Pearson correlation coefficients from CA1 hippocampal neurons two, four, and six days after transfection with Kv2.1-GFP. Each circle represents a different neuron. Bars are arithmetic means. 
Figure 7 Supplement 1: GxTX-594 labels CA1 hippocampal pyramidal neurons transfected with Kv2.1-GFP.

Two-photon excitation images rat CA1 hippocampal pyramidal neurons in brain slices as in Figure 7 A. Kv2.1-GFP (Left), GxTX-594 (Middle) and overlay (Right). Scale bars 10 $\mu \mathrm{m}$.
A. Two days after transfection with Kv2.1-GFP.
B. Four days after transfection with Kv2.1-GFP.
C. Six days after transfection with Kv2.1-GFP. 
Figure 8: GxTX-594 puncta on hippocampal CA1 neurons are sensitive to voltage stimulus

A. Single two-photon excitation optical section of fluorescence from CA1 pyramidal neurons in a cultured hippocampal slice after incubation with 100 nM GxTX-594. Scale bar is $5 \mu \mathrm{m}$.

B. GxTX-594 fluorescence from a single two-photon excitation optical section before and during depolarization of a whole cell patch-clamped neuron. Text labels of holding potential $(-70 \mathrm{mV}$ or $0 \mathrm{mV})$ indicate approximate position of the patch-clamp pipette.

Red arrows indicate stimulus-sensitive puncta, white arrows indicate stimulus-insensitive puncta. Left panel is the average fluorescence of the three frames at $-70 \mathrm{mV}$ before depolarization while the right panel is the average fluorescence of three frames after holding potential was stepped to $0 \mathrm{mV}$. Scale bar is $5 \mu \mathrm{m}$. Supplementary Movie 1 contains time-lapse images from this experiment.

C. ROIs used in analysis for panels D, E, and F. Same slice as panel B. ROI 1 contains the apparent plasma membrane of the cell body of the patch-clamped neuron, it was generated by drawing a path tracing the apparent plasma membrane and then expanding to an ROI containing 15 pixels on either side of the path (1.2 $\mu \mathrm{m}$ total width). ROI 2 contains the area 15-45 pixels outside the membrane path (1.2 $\mu \mathrm{m}$ total width). RO1 3 contains the area more than 45 pixels outside of the membrane path. ROI 0 contains the area more than 15 pixels inside the membrane path. Scale bar is $5 \mu \mathrm{m}$.

D. Fluorescence from each ROI shown in C. Squares represent ROI 0, circles represent ROI 1, upward triangles represent ROI 2 and upside-down triangles represent ROI 3. Background was defined as the mean fluorescence of ROI 0 during the experiment. $F_{\text {init }}$ was defined as the mean fluorescence of ROI 1 during the first six frames, after subtraction of background. Dotted lines represent the average fluorescence of the first six frames of each ROI. The voltage protocol is shown above.

E. Change in fluorescence during a $0 \mathrm{mV}$ step for different ROIs in multiple hippocampal slices. ROIs for each slice were defined by methods described in panel C. Circles represent mean fluorescence from six frames during $0 \mathrm{mV}$ stimulus $(F)$, normalized to mean fluorescence from same ROI in six frames before stimulus $\left(F_{\text {init }}\right)$. Circle color is consistent between ROIs for each hippocampal slice, red circles are from the slice shown in panel D. Black bars are arithmetic mean \pm standard error from 3 hippocampal slices. 
F. Kinetics of fluorescence change from ROI 1 during a $0 \mathrm{mV}$ step in multiple hippocampal slices. ROI 1 for each slice was defined by the method described in panel C. Lines are monoexponential fits (Eq.1). $k_{\Delta F}=6.8 \times 10^{-2} \pm 2.6 \times 10^{-2} \mathrm{~s}^{-1}$ (yellow), $6.8 \times 10^{-2} \pm 4.6 \mathrm{x}$ $10^{-2} \mathrm{~s}^{-1}$ (red), and $4.9 \times 10^{-2} \pm 2.1 \times 10^{-2} \mathrm{~s}^{-1}$ (green). The voltage protocol is shown above. Colors of individual circles indicate the same slices as panel $\mathrm{E}$.

G. Region of interest used in analysis for panels H, I, and J. Same image as panel C. The shaded ROI was generated by drawing a path tracing the apparent plasma membrane and then expanding to an ROI containing 5 pixels on either side of the path $(0.4 \mu \mathrm{m}$ total width). Numbers indicate puncta that appear as peaks in panel H. Scale bar is $5 \mu \mathrm{m}$.

H. A plot of the fluorescence intensity along the ROI shown in panel G before (red trace) and during (black trace) $0 \mathrm{mV}$ stimulus. Numbers above peaks correspond to puncta labeled in panel G. Red trace: mean fluorescence intensity during the three frames immediately before the stimulus, normalized to mean intensity of entire ROI (black dotted line), plotted against distance along path. Black trace: mean fluorescence intensity during three frames at $0 \mathrm{mV}$, normalized by the same $F_{\text {init }}$ value as the red trace.

I. Kinetics of fluorescence change of individual puncta from panel G. Puncta intensity are average intensity of points extending to half maxima of each peak in panel H. Asterisks indicate mean fluorescence intensity of puncta 1 (pink), 4 (red), and 5 (dark red). Lines are monoexponential fits (Eq.1). $k_{\Delta F}=7.1 \times 10^{-2} \pm 2.9 \times 10^{-2} \mathrm{~s}^{-1}$ (pink), $6.7 \times 10^{-2} \pm 2.5 \mathrm{x}$ $10^{-2} \mathrm{~s}^{-1}$ (red) and $1.2 \times 10^{-1} \pm 5.6 \times 10^{-2} \mathrm{~s}^{-1}$ (dark red). Fits to other puncta had standard deviations larger than $k_{\Delta F}$ values, and were excluded. $F_{\text {init }}$ was defined as the mean background subtracted fluorescence of the puncta during the six frames before stimuli. The voltage protocol is displayed above. Blue line is prediction from Scheme I.

J. Comparison of fluorescence change of puncta and inter-puncta regions in response to 0 $\mathrm{mV}$ stimulus. The regions before stimulus shown in the red line of panel $\mathrm{H}$ that had $F / F_{\text {init }} \geq 1$ (above average) were binned separately from regions with $F / F_{\text {init }}<1$. The mean fluorescence of each region during $0 \mathrm{mV}$ stimulus (panel H black trace) was compared to the fluorescence before stimulus (panel H red trace). Circles indicate values from three independent hippocampal slices, colors indicate same slices as panel E and F. Black bars are arithmetic mean \pm standard error. 
K. Rate of fluorescence change of GxTX-594 after a $0 \mathrm{mV}$ stimulus; from puncta (as in panel I), ROI 1 (as in panel F) or Kv2.1-CHO cells in 100 nM GxTX-594. Kv2.1-CHO cells were imaged at the same temperature as neurons $\left(30^{\circ} \mathrm{C}\right)$ using neuronal intracellular solution. Normal CHO extracellular solution (CE) was used for Kv2.1-CHO cell experiments. Kv2.1-CHO measurements were made by airy disk confocal imaging. Black bars are mean \pm SEM from data shown. Dashed blue line is $k_{\Delta F}=6.31 \times 10^{-2} \mathrm{~s}^{-1}$ prediction of Scheme I. 


\section{Table 1}

Parameters used for calculations with Scheme I Model

\begin{tabular}{ll} 
Parameter & \multicolumn{1}{c}{ Value } \\
\hline$k_{\text {on,resting }}$ & $0.30 \mu \mathrm{M}^{-1} \mathrm{~s}^{-1}$ \\
$k_{\text {off,resting }}$ & $0.0081 \mathrm{~s}^{-1}$ \\
& \\
$k_{\text {on, activated }}$ & $0.21 \mu \mathrm{M}^{-1} \mathrm{~s}^{-1}$ \\
$k_{\text {off, activated }}$ & $0.39 \mathrm{~s}^{-1}$ \\
& \\
$V_{1 / 2, \text { unlabeled }}$ & $-32 \mathrm{mV}$ \\
$V_{1 / 2, \text { labeled }}$ & $41 \mathrm{mV}$ \\
$z$ & $1.5 e_{0}$
\end{tabular}


Figure 1 Supplement 1

A

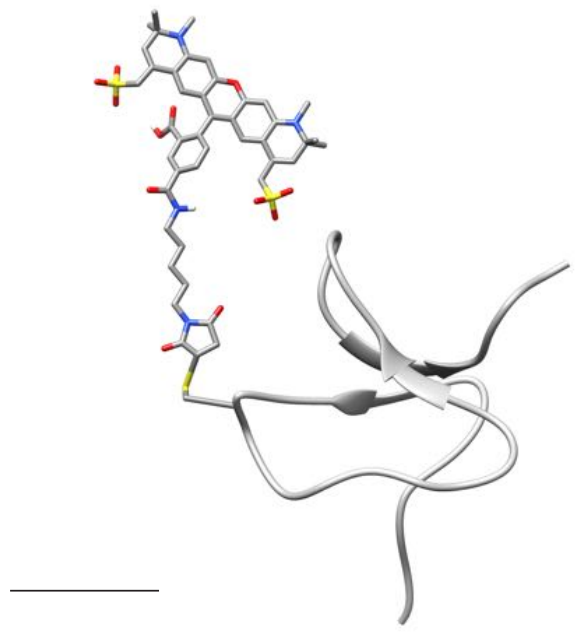

C

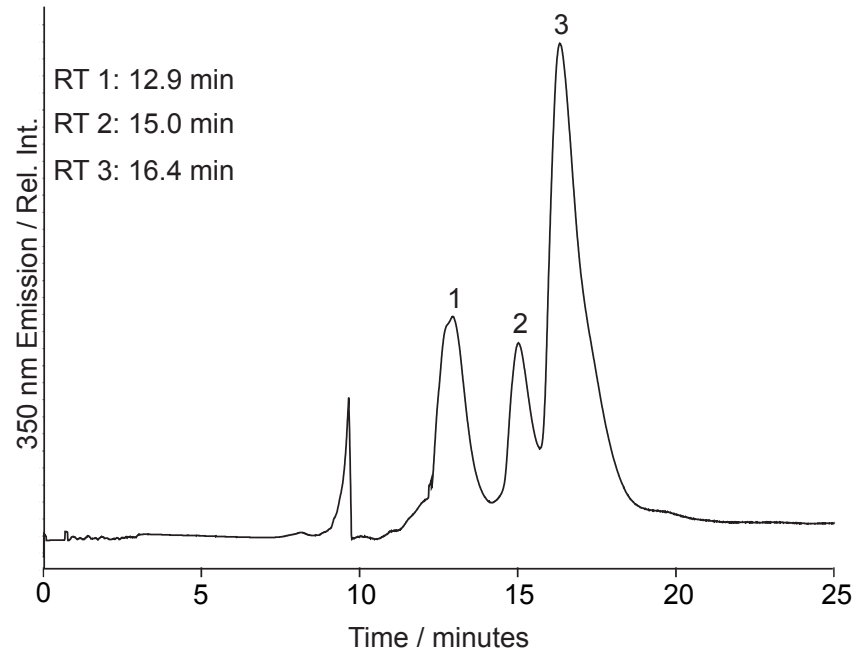

B
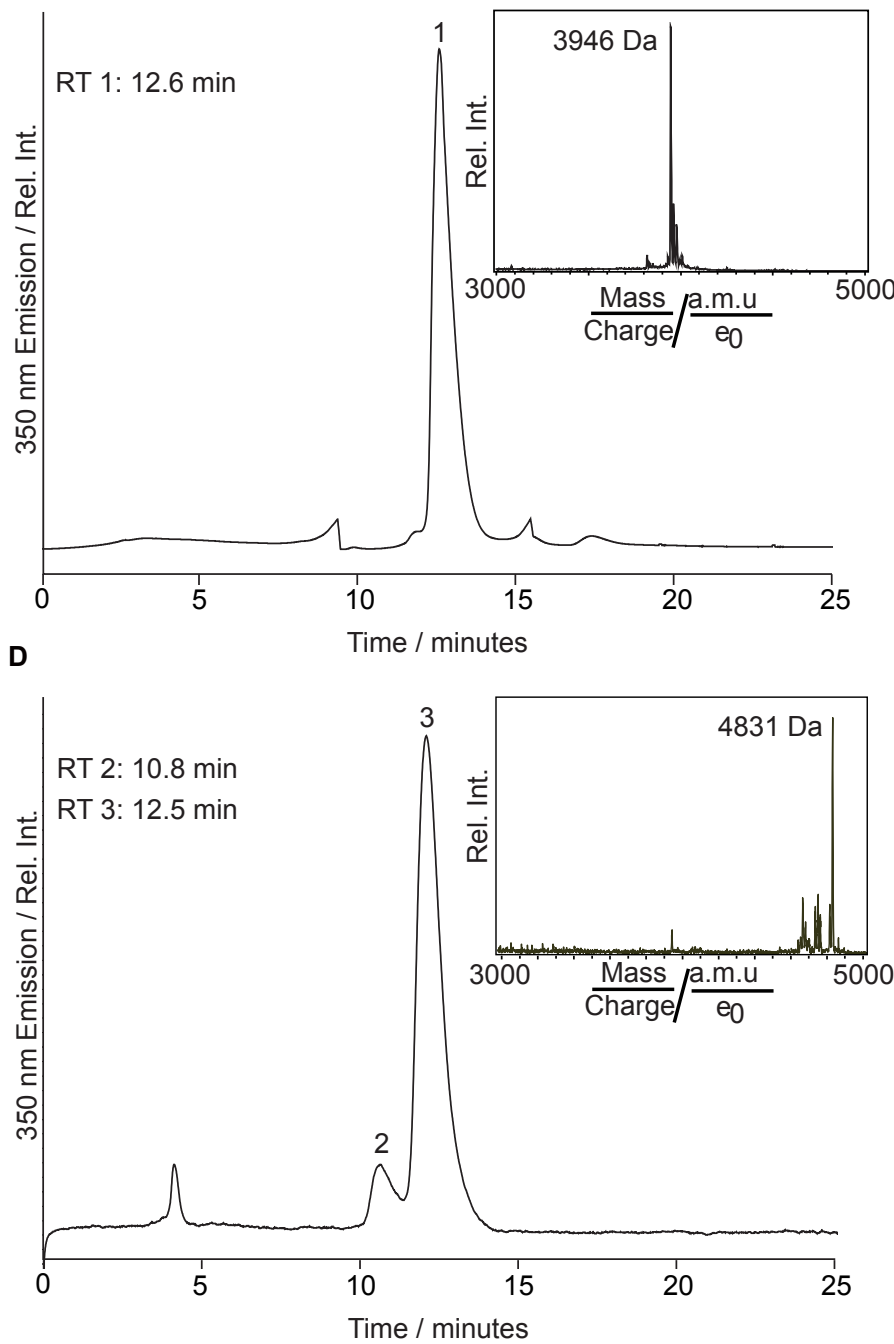


\section{Figure 3 Supplement 2}

A

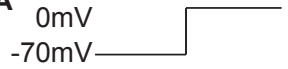

$100 \%$
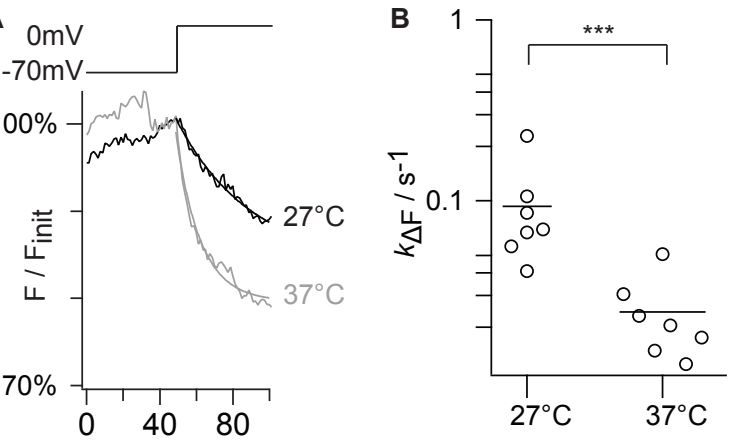

Time / sec 
Figure 4

A
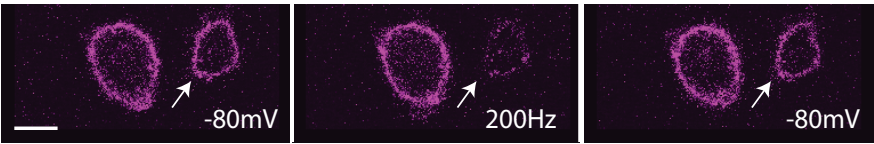

B

$200 \mathrm{~Hz}$
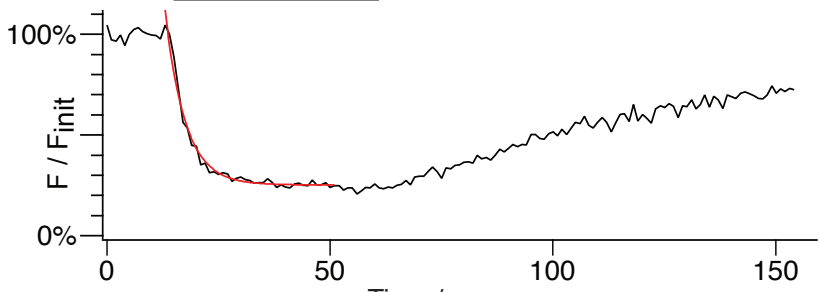

Time / sec

\section{C}

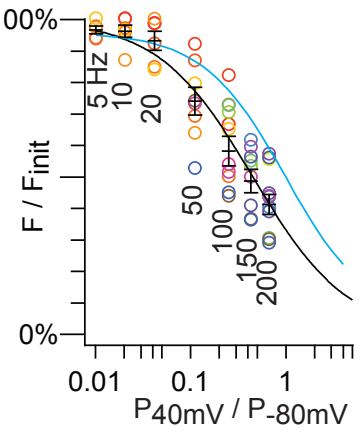

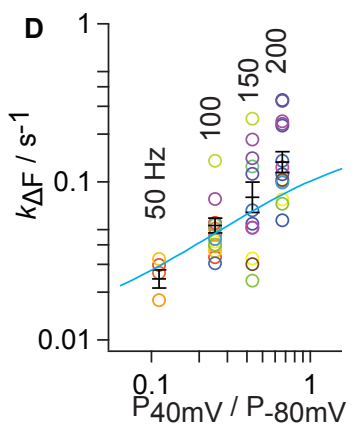


Figure 5

A Kv2.1 Pactivated/P resting

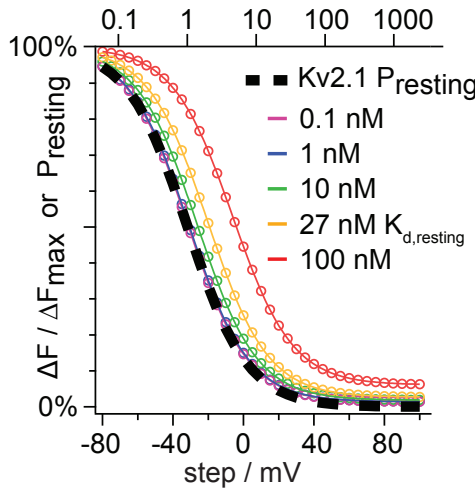

B Kv2.1 $\mathrm{P}_{\text {activated }} / \mathrm{P}_{\text {resting }}$

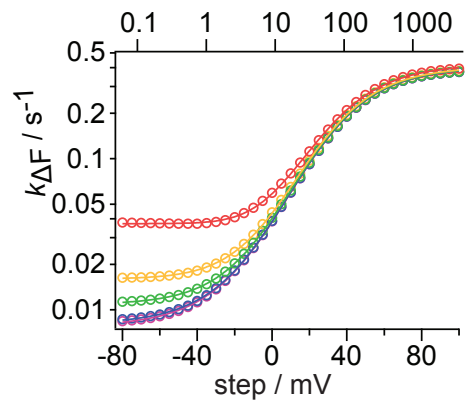




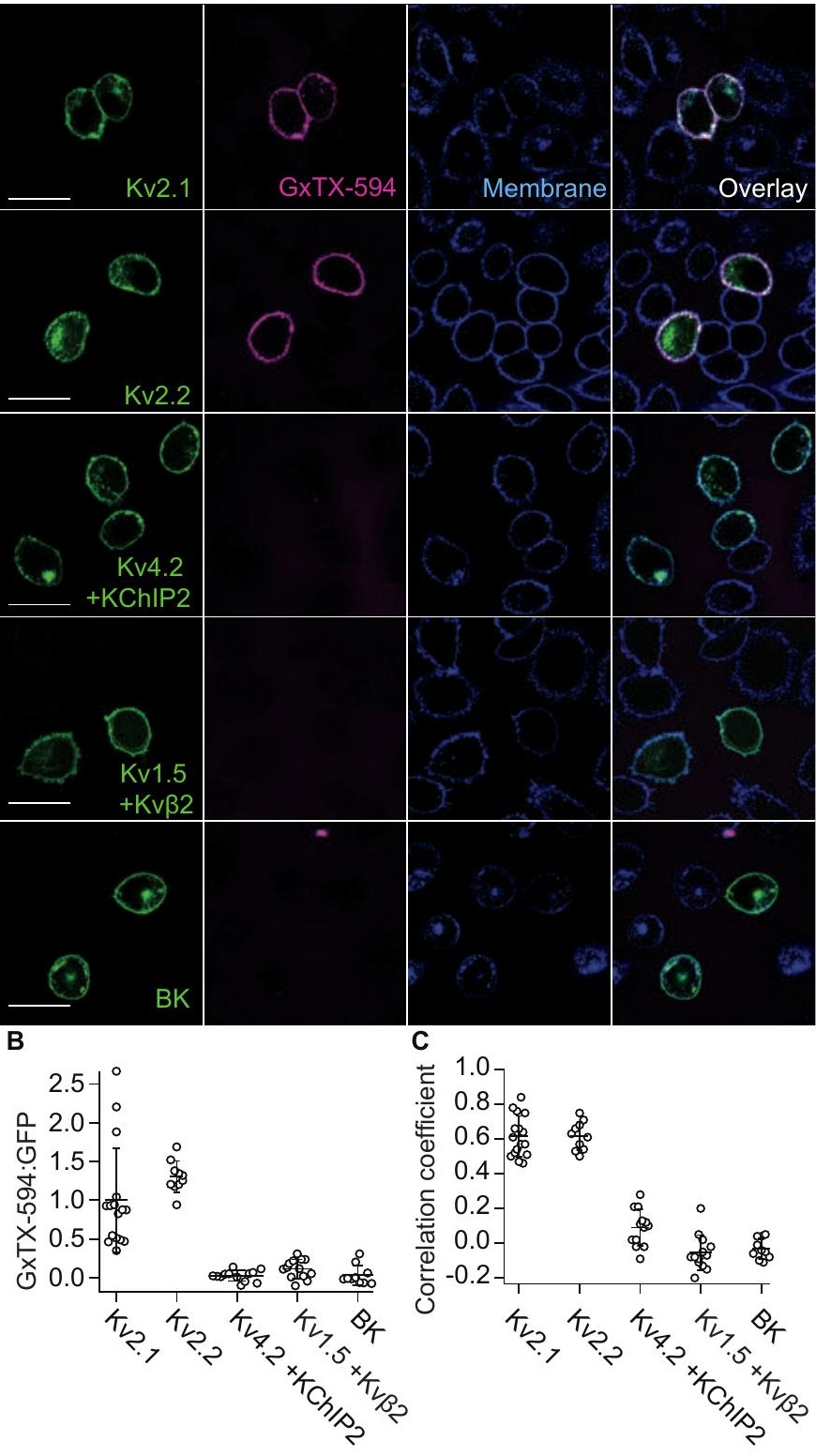


Figure 6 Supplement 1
A
B
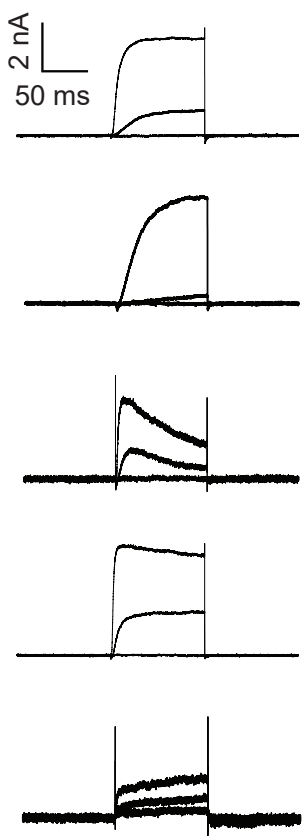

C

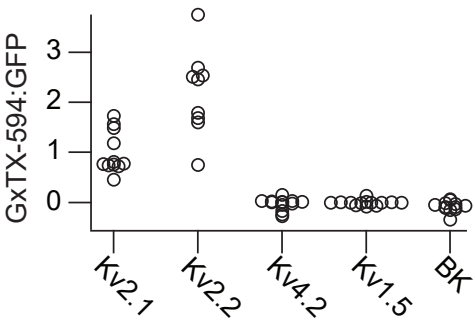

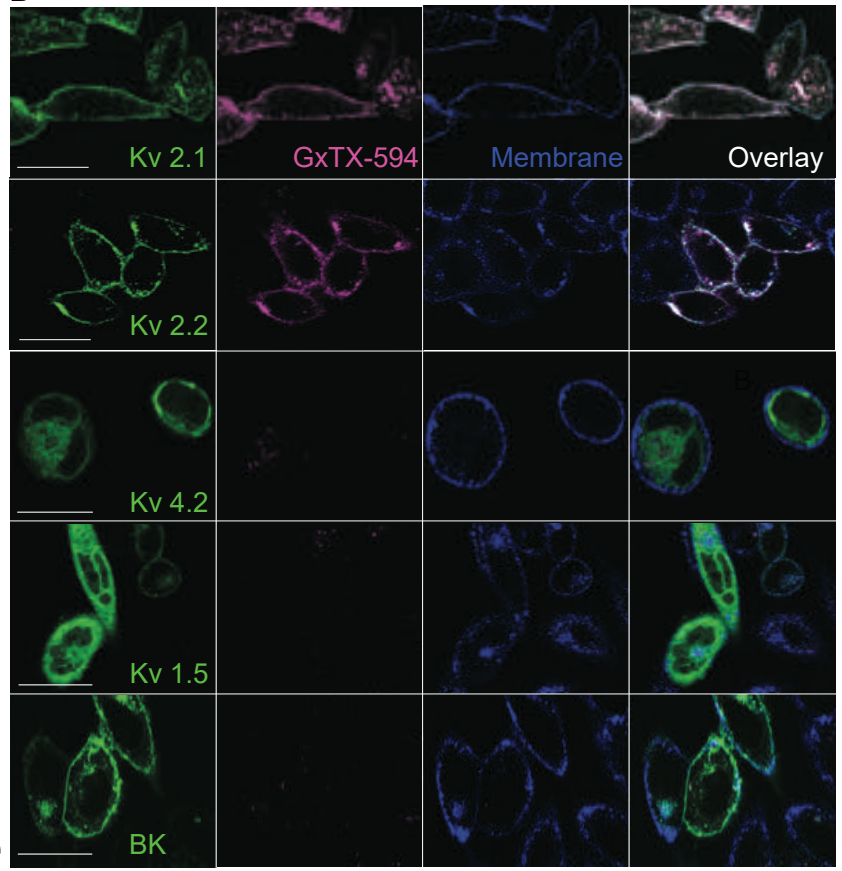

D

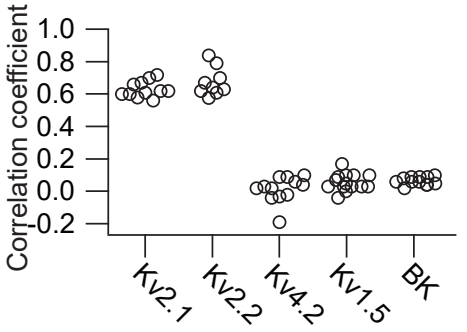


Figure 7

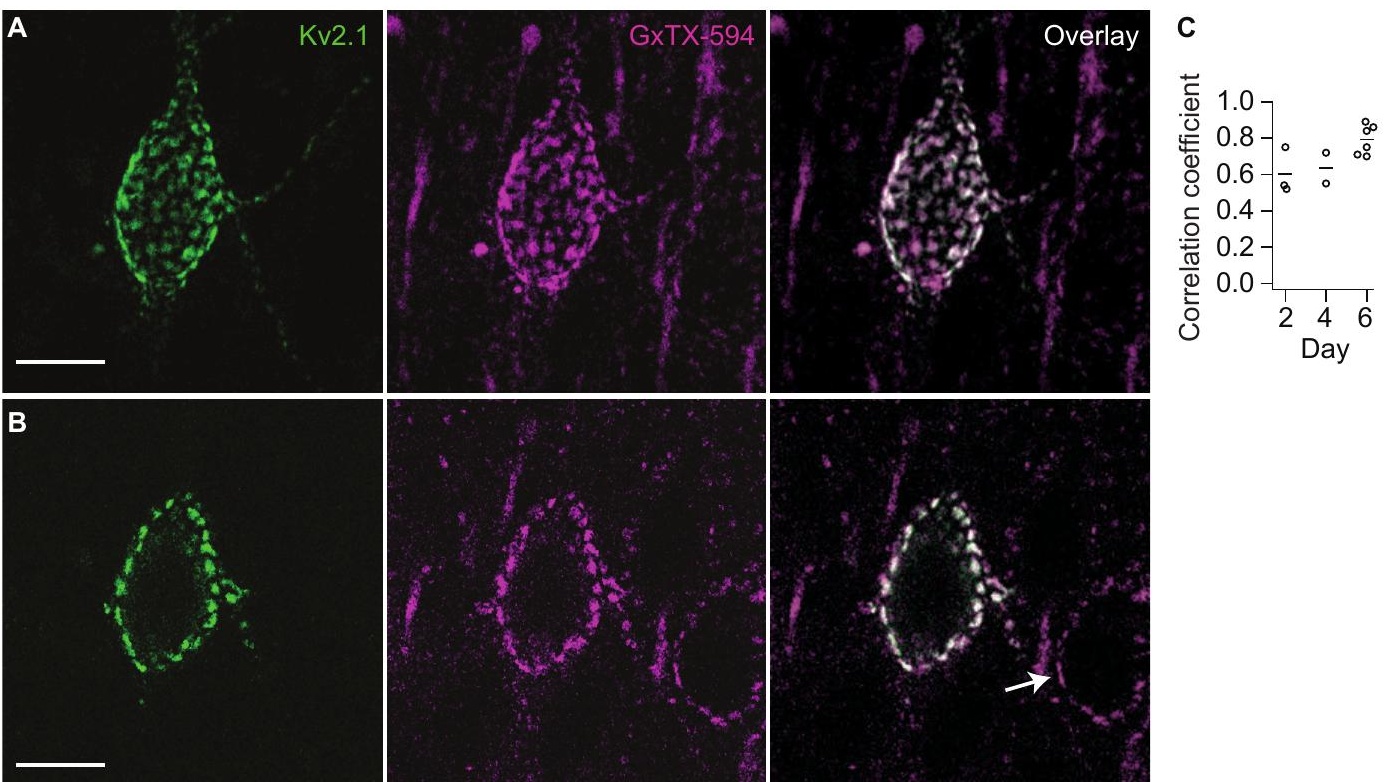


A

Kv2.1-GFP

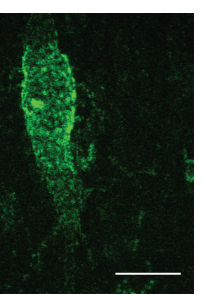

B

Kv2.1-GFP
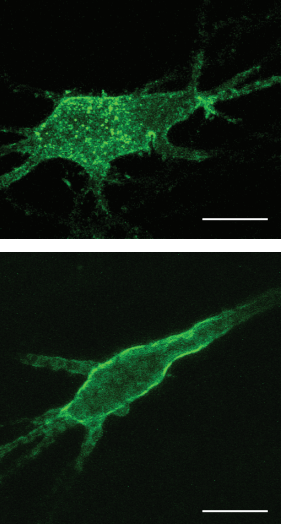

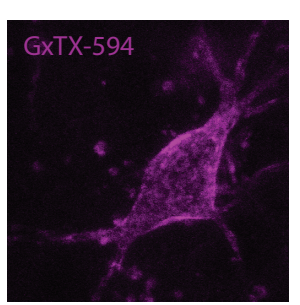

Overlay
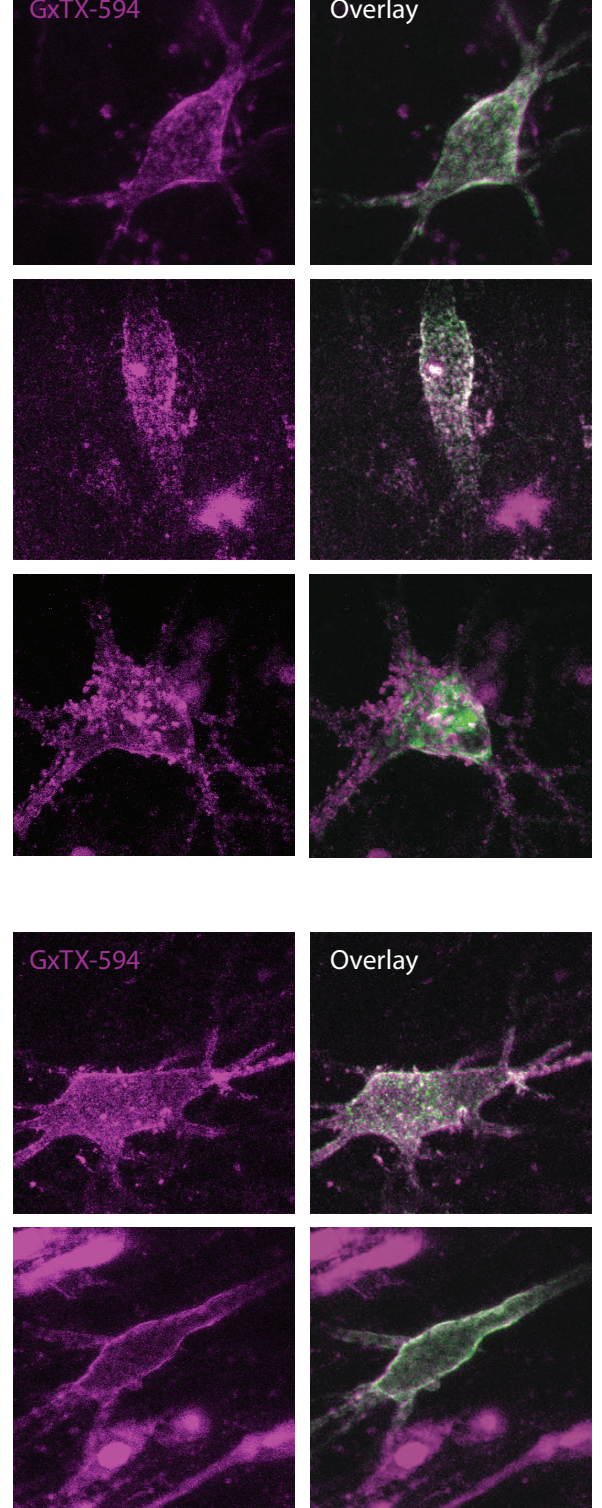

Overlay
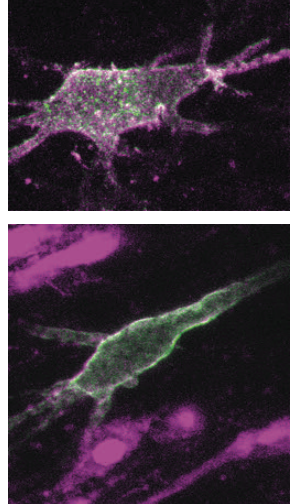

\section{C}

Kv2.1-GFP
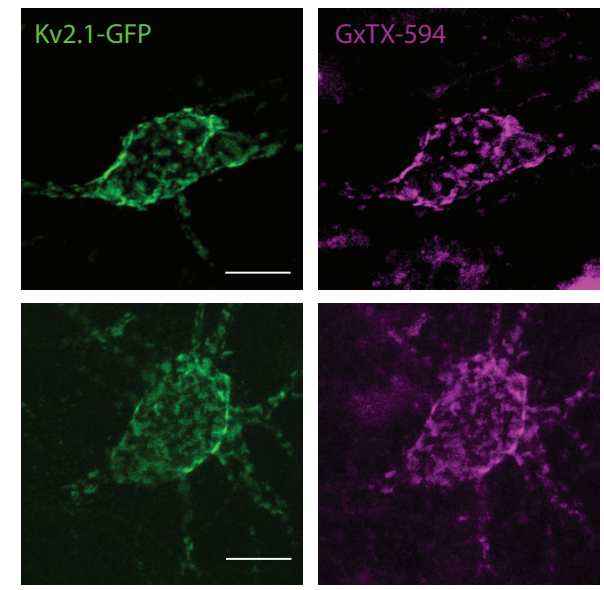
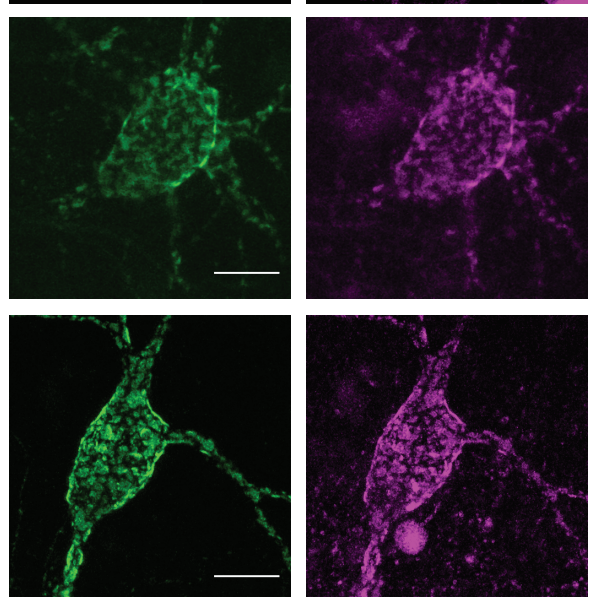

Overlay
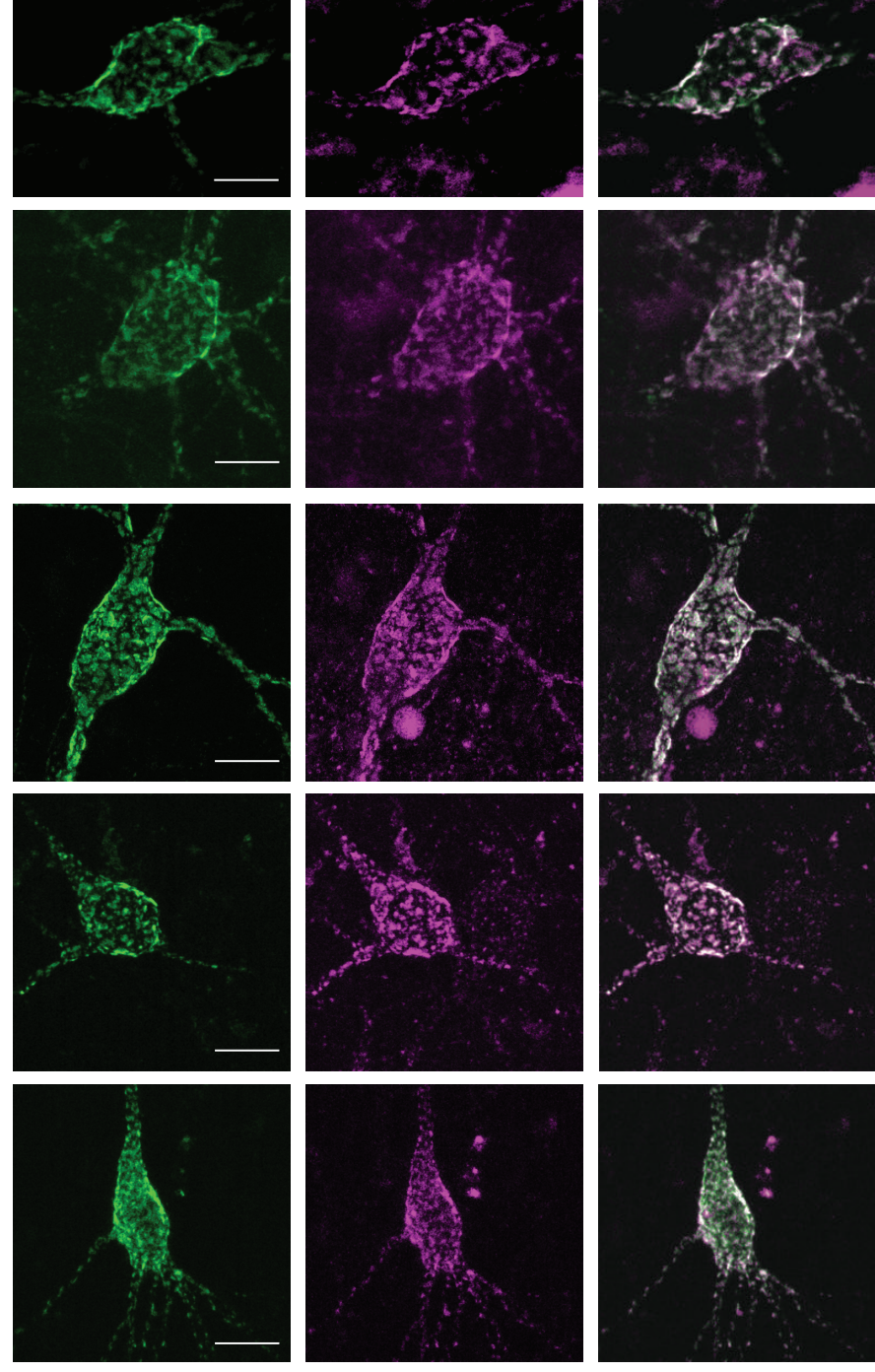
